\title{
Transcription of Repeats Activates INterferon (TRAIN) in response to chromatin destabilization induced with anti-cancer small molecule
}

Katerina Leonova', Alfiya Safina', Elimelech Nesher ${ }^{1,2}$, Poorva Sandlesh ${ }^{1}$, Rachel Pratt ${ }^{1}$, Catherine Burkhart ${ }^{3}$, Britney Lipchick ${ }^{1}$, Costakis Frangou ${ }^{1}$, Igor Koman ${ }^{2}$, Jianmin Wang ${ }^{4}$, Kirill Kirsanov $^{5}$, Marianna G. Yakubovskaya ${ }^{5}$, Andrei V. Gudkov ${ }^{1}$, Katerina Gurova ${ }^{1, \#}$

1 - Department of Cell Stress Biology, Roswell Park Cancer Institute, Buffalo, NY, 14263, USA

2 - Department of Molecular Biology, Ariel University, Ariel 40700, Israel

3 - Buffalo BioLabs, 71 High St, Buffalo, NY 14203, USA

4 - Department of Bioinformatics, Roswell Park Cancer Institute, Buffalo, NY, 14263, USA

5 - Department of Chemical Carcinogenesis, Institute of Carcinogenesis, Blokhin Cancer Research Center RAMS, Moscow 115478, Russia

\#Corresponding author: Katerina Gurova, Department of Cell Stress Biology, Roswell Park Cancer Institute, Elm and Carlton Streets, Buffalo, NY 14263, USA; Tel\# 1-716-845-4760, Fax\# 1-716-845-3944, e-mail: katerina.gurova@roswellpark.org

\section{Funding}

This work was supported by Incuron LLC (K.G.), and by National Cancer Institute grants R01CA197967 (K.G.) and P30CA016056 (Roswell Park Cancer Center). 


\begin{abstract}
The anticancer activity of genotoxic agents has been intensively studied, while the mechanisms of action of drugs destabilizing the epigenome are far less understood. We previously found that DNA hypomethylation in the absence of p53 leads to transcriptional desilencing of repetitive DNA elements, such as pericentromeric repeats and endogenous retroelements, which is associated with an interferon type I response, a phenomenon we named TRAIN (Transcription of Repeats Activates INterferon). Here, we report that curaxin, a small molecule anticancer drug candidate, which destabilizes nucleosomes via disruption of histone/DNA interactions, can induce TRAIN independently of the p53 status of a cell. Furthermore, curaxin inhibits oncogeneinduced transformation in an interferon-dependent manner, suggesting that cancer prevention by curaxin, previously attributed to its p53-activating and NF-kappaB-inhibiting activities, may also involve the induction of the interferon response to epigenetic derepression of the cellular "repeatome." Moreover, we observed that another type of drugs decondensing chromatin, histone deacetylase inhibitor, also induces TRAIN. Thus, we proposed that TRAIN may be one of the mechanisms ensuring epigenetic integrity of cells via elimination of cells with desilenced chromatin.
\end{abstract}




\section{Introduction}

Control of the integrity of genetic information in cells includes the activation of the DNA damage response, DNA-repair pathways and elimination of cells with damaged DNA (reviewed in (Miller, 2010, Wang \& Lindahl, 2016)). The control of the integrity of epigenetic information is equally important and critical for the development and function of multicellular organisms, but far less studied. Epigenetic information is stored as chromatin, the highly-organized complex of DNA, histone proteins and their chemical modifications (reviewed in (Campos, Stafford et al., 2014, Miska \& Ferguson-Smith, 2016)). Destabilization of chromatin should lead to the dysregulation of the cellular transcriptional program and loss of cell identity. One of the examples that demonstrate the high stability of the cellular epigenome is the well-known, extremely low efficiency of reprogramming a differentiated cell (reviewed (Ebrahimi, 2015, Hussein \& Nagy, 2012)). Another example is the absence of one common "cancer cell" phenotype: transcriptome analysis has clearly demonstrated that tumors, including cell lines propagated for years in culture, bear easily identifiable traits of the tissue of origin in their transcriptional program (TCGA data). Nonetheless, we do not know what mechanisms control the stability of chromatin in cells, i.e., whether there is any stress response to chromatin destabilization or negative selection against cells that lose epigenetic integrity.

One of the reasons for this deficit was the absence of tools to induce "chromatin damage" without simultaneous introduction of DNA damage. This possibility appeared, when we found anti-cancer small molecules, known as curaxins, that were able to cause chromatin disassembly in cells in the absence of DNA damage (Gasparian, Burkhart et al., 2011), (Safina, Cheney et al., 2017). These small molecules were identified in a phenotype-based screening for the ability to simultaneously activate p53 and inhibit NF-kappaB (Gasparian et al., 2011). Our search for the mechanism of action of curaxins resulted in the discovery that they bind DNA via intercalation of the carbazole body accompanied by the protrusion of two side chains into the major groove and a third side chain into the minor groove of DNA. Curaxins have no effect on DNA chemical structure, i.e., they do not cause any DNA damage in mammalian cells. However, their binding to DNA changes both the helical shape and flexibility of DNA and reduces its negative charge (Safina et al., 2017).

The structural unit of chromatin in eukaryotic cells is the nucleosome, which consists of a core of positively charged histone proteins wrapped in negatively charged DNA. The stability of the nucleosome is based on the electrostatic interactions between the histones and phosphate backbone of DNA, which are supported by several precise spatially-oriented points of contact between histone amino acids and the base pairs of DNA (Luger, Mader et al., 1997). When nucleosomal DNA is unwrapped, the core becomes unstable due to the repulsion of the positively charged histones from each other. Alterations of DNA helical shape, charge and flexibility, caused by curaxins, force DNA to dissociate from the core in vitro and in vivo (Safina et al., 2017). At lower concentrations of curaxin CBL0137, DNA is first unfolded from the outer parts of the nucleosome, i.e., from $\mathrm{H} 2 \mathrm{~A} / \mathrm{H} 2 \mathrm{~B}$ dimers located at both sides of the inner $\mathrm{H} 3 / \mathrm{H} 4$ tetramer, which leads to the detachment of the $\mathrm{H} 2 \mathrm{~A} / \mathrm{H} 2 \mathrm{~B}$ dimer(s) and exposure of the surface of the $\mathrm{H} 3 / \mathrm{H} 4$ tetramer. At higher CBL0137 concentrations, DNA is unwrapped from the inner $\mathrm{H} 3 / \mathrm{H} 4$ tetramer, which leads to complete nucleosome disassembly (Safina et al., 2017). At the regions where the DNA helix loses histone cores, it becomes significantly under twisted, which in principle may be alleviated by topoisomerases or free rotation of DNA. However, in cells, free rotation is impossible due to the length of DNA and the binding to multiple proteins. Moreover, topoisomerases cannot cleave DNA in the presence of curaxins (Safina et al., 2017). Under these conditions, the excessive energy of negative supercoiling causes base unpairing and DNA transition from B-DNA into alternative non-B DNA structures. We have shown a massive transition of right-handed B-DNA in cells treated with curaxin CBL0137 into the left-handed ZDNA form (Safina et al., 2017). Thus, treatment of cells with CBL0137 leads to dose-dependent 
destabilization and disassembly of chromatin in the absence of DNA damage and, most importantly, of the classical DNA damage response, providing an opportunity to study how a cell reacts to chromatin damage and the role of chromatin perturbations in the anti-cancer activity of curaxins.

The first type of response that we observed in curaxin-treated cells was the activation of p53, a well-known reaction of cells to DNA damage. However, no phosphorylation of p53 Nterminal serines, which are obligatory markers of the DNA damage response, was detected in curaxin-treated cells. Furthermore, there was no activation of DNA-damage sensitive kinases, such as ATM, ATR, and DNA-PK. Instead, p53 in curaxin-treated cells was phosphorylated at serine 392 by casein kinase 2 (CK2) that formed a complex with the histone chaperone Facilitates Chromatin Transcription (FACT) (Gasparian et al., 2011). FACT consists of two conservative proteins present in all eukaryotes, Suppressor of Ty 16 (SPT16) and Structure Specific Recognition Protein 1 (SSRP1). In basal conditions, FACT binds histone oligomers via different domains of SSRP1 and SPT16, weakening their contact with DNA, and making the latter available for transcription (Valieva, Armeev et al., 2016, Winkler \& Luger, 2011). FACT binding prevents histone oligomers from dissociating while DNA is transcribed (Belotserkovskaya, Oh et al., 2003). We have found that nucleosome disassembly caused by curaxin opens multiple FACT binding sites, which are normally hidden inside the nucleosome. Chromatin unfolding occurs first in heterochromatic regions, and all cellular FACT is rapidly relocated into these regions and depleted from the nucleoplasm (Safina et al., 2017). We named this phenomenon chromatin-trapping or c-trapping. Although curaxins do not bind and inhibit FACT directly, they cause exhaustion of FACT by trapping it in heterochromatin. Therefore, c-trapping is equivalent to functional FACT inhibition. We also observed that FACT not only binds partially disassembled nucleosomes but also Z-DNA via the CID (c-terminal intrinsically disordered) domain of the SSRP1 subunit (Safina et al., 2017). Importantly, it was already known that the immediate neighboring domain, HMG (high mobility group), also binds non-B DNA, bent or cruciform (Gariglio, Ying et al., 1997, Krohn, Stemmer et al., 2003, Yarnell, Oh et al., 2001). In all cases of SSRP1 binding to DNA, there is a CK2-mediated signal for p53 activation (Gasparian et al., 2011, Krohn et al., 2003). Therefore, c-trapping may be part of the general response to the destabilization of chromatin and may serve to recruit FACT to the regions of potential nucleosome loss to prevent this loss and to restore chromatin structure.

However, there are many unclear issues within this model. Among the most immediate are two related questions: (i) what are the consequences, besides c-trapping, of nucleosome destabilization and chromatin unfolding in cells? (ii) Are all the effects of curaxins explained by the functional inactivation of FACT? In this study, we tried to answer these questions starting from the comparison of the effects of CBL0137 on transcription. We found that independently of the presence of FACT, CBL0137 activates transcription from heterochromatic regions normally silenced in cells, including centromeric and pericentromeric repeats and endogenous retroviral elements, resulting in the accumulation of double-stranded RNAs (dsRNA) in cells and activation of the type I interferon (IFN) response. This phenomenon, named TRAIN (Transcription of Repeats Activates INterferon) (Leonova, Brodsky et al., 2013) was observed previously upon DNA demethylation (Chiappinelli, Strissel et al., 2015, Guryanova, Shank et al., 2016, Roulois, Loo Yau et al., 2015). Although IFN activation has been traditionally viewed as part of an antiviral defense, TRAIN may present a more general cell response to the problems associated with chromatin organization in cells or a defense against loss of epigenetic integrity. We proposed that the reason for TRAIN in CBL0137-treated cells is the direct effect of the drug on nucleosome structure leading to the opening of chromatin. 


\section{Material and Methods}

Chemicals, reagents, and plasmids: CBL0137 was provided by Incuron, LLC. Trichostatin A was purchased from Sigma-Aldrich. Poly I:C (polyinosinic:polycytidylic acid) was purchased from Tocris Bioscience. ISRE-mCherry reporter plasmid was purchased from Cellecta. Two ZBP1 gRNA, control gRNA, and CRISPR/Cas9 lentiviral single vector plasmids and mCherrytagged histone H1.5 were purchased from GeneCopoeia. GFP-tagged SSRP1 was previously described in (Safina et al., 2017).

Cells: HeLa, HepG2, and HT1080 cells were obtained from ATCC and maintained in DMEM with $5 \%$ Fetal Bovine Serum (FBS) and $50 \mu \mathrm{g} / \mathrm{ml}$ of penicillin/streptomycin. Mouse squamous cell carcinoma SCCVII cells were obtained from Dr. Burdelya (Roswell Park Cancer Institute (RPCI), Buffalo, NY). Preparation and maintenance of HeLa-TI cell populations containing integrated avian sarcoma genome with silent green fluorescent protein (GFP) gene were described previously (Poleshko, Einarson et al., 2010, Shalginskikh, Poleshko et al., 2013).

Isolation and cultivation of mouse embryonic fibroblast (MEF) cells: MEFs were isolated

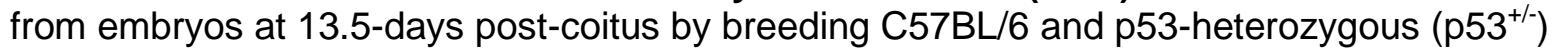
mice or C57BL/6 IFNAR-null and p53-heterozygous females and males as described in the protocol http://www.molgen.mpg.de/ rodent/MEF_protocol.pdf. Cells from each embryo were individually plated. DNA was isolated from individual embryos using the PureLink ${ }^{\mathrm{TM}}$ Genomic DNA Kit (Invitrogen). The genotype of the embryos was determined by PCR with the following primers: $153^{+/+}$ACAGCGTGGTGGTACCTTAT; $553^{+/-}$TATACTCAGAGCCGGCCT; $p 53^{-/-}$ TCCTCGTGCTTTACGGTATC; IFNARko 5'common 5'-

ATTATTAAAAGAAAAGACGAGGAGGCGAAGTGG-3'; IFNARko 3'WTallele 5'AAGATGTGCTGTTCCCTTCCTCTGCTCTGA-3'; IFNARko Neo 5'-

CCTGCGTGCAATCCATCTTG-3'. MEF cells were cultured in DMEM supplemented with 10\% FBS and $50 \mu \mathrm{g} / \mathrm{ml}$ penicillin/streptomycin for no more than eight passages.

Reverse transcriptase-PCR: CDNA was made from $1 \mu \mathrm{gg}$ total RNA isolated by TRIzol (Invitrogen) using the iScript cDNA Synthesis Kit (BioRad). The PCR reaction was carried out in accordance with the manufacturer's protocol using Taq PCR Master Mix (USB) in a reaction volume of $25 \mathrm{\mu l}$ with $100 \mathrm{ng}$ of the following primers: mouse Irf7 (sense: 5'CAGCCAGCTCTCACCGAGCG; antisense: 5'-GCCGAGACTGCTGCTGTCCA), mouse Ifit3 (Isg49) (sense: 5'-GCCGTTACAGGGAAATACTGG; antisense: 5'CCTCAACATCGGGGCTCT); human ISG56 (sense: 5'- CCCTGCAGAACGGCTGCCTA; antisense: 5'-AGCAGGCCTTGGCCCGTTCA); mouse Isg15 (sense: 5'AAGAAGCAGATTGCCCAGAA; antisense: 5'- TCTGCGTCAGAAAGACCTCA); mouse Usp18 (sense: 5'-AAGGACCAGATCACGGACAC; antisense: 5'- CACATGTCGGAGCTTGCTAA), mouse- $\beta$-actin (sense: 5'- GCTCCGGCATGTGCAA; antisense: 5'AGGATCTTCATGAGGTAGT-3'), human ZBP1 (sense: 5'- TGCAGCTACAATTCCAGAGA; antisense: 5'- GAAGGTGCCTGCTCTTCATC.

Western immunoblotting: Protein extracts were prepared by lysing cells or tissues in RIPA buffer (Sigma-Aldrich) containing protease inhibitor cocktail (Sigma-Aldrich). Extracts were spun down at $10,000 \times \mathrm{rpm}$ for $10 \mathrm{~min}$ at $4^{\circ} \mathrm{C}$ to obtain the soluble fraction. Protein concentrations were determined using the BioRad Protein Assay (Bio-Rad). Equal amounts of protein were run on $4-20 \%$ precast gradient gels (Invitrogen) and blotted/transferred to Immobilon-P membrane (Millipore). Membranes were blocked with 5\% non-fat milk-TBS-T buffer for one hour and incubated overnight with primary antibodies. The following antibodies were used: 1:10000 antiISG49 and anti-ISG56 (a kind gift from Dr. Ganes Sen, Cleveland Clinic). $\beta$-Actin (Santa Cruz) antibodies were used to verify equal protein loading and transfer. Anti-mouse and anti-rabbit 
secondary horseradish peroxidase-conjugated antibodies were purchased from Santa Cruz. ECL detection reagent (GE Healthcare) was used for protein visualization on autoradiography film (Denville Scientific).

Northern hybridization: Mouse cDNA probes for SINE B1 (sense: 5'GCCTTTAATCCCAGCACTTG, antisense: 5'-CTCTGTGTAGCCCTGGTCGT), were made by reverse-PCR from the total RNA of MEF cells. The cDNAs were labeled with $\left[\alpha^{32} \mathrm{P}\right]-\mathrm{dCTP}$, using the Random Primed DNA Labeling Kit following the manufacturer's protocol (Roche). Total RNA was extracted from cells that were either untreated or treated with $10 \mu \mathrm{M}$ of 5 -aza-dC for 48 hours or $0.5 \mathrm{uM}$ of CBL0137 for 24 hours using Trizol (Invitrogen). Total RNA (5 $\mu \mathrm{g}$ ) was loaded onto each lane, electrophoresed in an agarose-formaldehyde gel, and transferred onto a Hybond-N membrane (Amersham Pharmacia Biotech). After UV crosslinking, the transfers were hybridized with $\left[\alpha^{32} \mathrm{P}\right]-\mathrm{dCTP}$-labeled probes and analyzed by autoradiography at $-80^{\circ} \mathrm{C}$.

Immunofluorescent staining: Cells were plated in $35 \mathrm{~mm}$ glass bottom plates from MatTek Corporation (Ashland, MA). After treatment, cells were washed with PBS and fixed in $4 \%$ paraformaldehyde at room temperature for $15 \mathrm{~min}$. For Z-DNA staining, a $4 \%$ paraformaldehyde solution containing $0.1 \%$ Triton-X100 in PBS was added to cells for 15 min immediately after removal of media. Cells were then washed three times with PBS. Blocking was done in $3 \%$ BSA, $0.1 \%$ Triton-X100 in PBS. Primary antibodies: Z-DNA from Abcam (cat\# ab2079) was used at 1:200 dilution. dsRNA antibody (J2) from Scicons (Hungary) was used at 1:50 dilution. AlexaFluor 488 or 594 donkey anti-mouse (Invitrogen, cat\# A21206; 1:1000) and AlexaFluor 594 donkey anti-sheep (Jackson ImmunoResearch, cat\# 713-585-147; 1:500) were used as secondary antibodies. Antibodies were diluted in 0.5\% BSA + 0.05\% Triton X100 in PBS. After each antibody incubation, cells were washed three times with $0.05 \%$ Triton X100 in PBS. For DNA counterstaining, $1 \mu \mathrm{g} / \mathrm{ml}$ solution of Hoechst 33342 in PBS was used. Images were obtained with a Zeiss Axio Observer A1 inverted microscope with N-Achroplan 100×/1.25 oil lens, Zeiss MRC5 camera, and AxioVision Rel.4.8 software.

Flow cytometry was performed on LSR Fortessa A and BD LSRII UV A Cytometers (BD Biosciences, San Jose, CA, USA). Obtained data were analyzed by the WinList 3D program (Verity Software House, Topsham, ME, USA).

Microarray hybridization, RNA-sequencing, and analyses: Total RNA from cells was isolated using TRIzol reagent (Invitrogen). Three biological replicates of each condition were used for microarray hybridization and two for RNA-sequencing. RNA processing, labeling, hybridization, generation of libraries, and sequencing were performed by the Genomics Shared Resource (RPCI). MouseWG-6 v2.0 Expression BeadChip array (Illumina) was used for hybridization. The TruSeq Stranded Total RNA Library Prep Kit with Ribo-Zero Mouse kit (Illumina) was used for library preparation. Sequencing was done using Illumina HiSeq 2000 system. Gene expression data were analyzed using GeneSpring GX for microarray hybridization and Strand NGS for RNA-sequencing (Agilent Genomics, Santa Clara, CA, USA). GSEA was done using MSigDB (Broad Institute) and MetaCore software (Thompson Reuter).

The GRCm38.p5 (Genome Reference Consortium Mouse Reference 38) assembly was used for all mouse data, and the set of annotated repeat types was taken from the Repbase database (Kapitonov \& Jurka, 2008). Sailfish version 0.6.3 aligner was used to quantify the abundance of previously annotated RNA transcripts from RNA-seq data (Patro, Mount et al., 2014). Analyses were performed with a modified $k$-mer size of $k=17$ and used 16 concurrent threads ( $p$ 16). Sailfish was run with the poly-A option, which discards k-mers consisting of k consecutive A's or T's, and bias correction was enabled. Importantly, a read was associated with a particular 'repeat' type if it satisfied the following criteria: a) The read aligned to a single or multiple locations within the canonical sequence of that repeat type, or annotated instances of that 
repeat type within the genome, incorporating $13 \mathrm{bp}$ (half of the read length) genomic sequences flanking the annotated instances. b) No alignment of such or better quality to canonical or instance sequences associated with any other annotated repeat types could be obtained. An optional masking procedure, designed to exclude reads potentially originating from unannotated repeat types, added a third requirement. c) No alignment of such or better quality to any portion of the genome assembly that is not associated with the annotated instances of that repeat type could be obtained. Collectively, the combined repeat assembly file contained a single FASTA entry for each repeat type as defined in the Repbase database. The Transcripts per Million quantification number was computed as described in (Wagner, Kin et al., 2013), (Qian \& Huang, 2005) and is meant as an estimate of the number of transcripts, per million observed transcripts, originating from each target transcript. Its benefit over the F/RPKM measure is that it is independent of the mean expressed transcript length (i.e. if the mean expressed transcript length varies between samples, for example, this alone can affect differential analysis based on the K/RPKM). Finally, we used the variational Bayesian EM algorithm integrated into sailfish, rather than the "standard" EM algorithm, to optimize abundance estimates. P values were corrected using an FDR correction using the method.

Statistical analyses: Unpaired t-test was used for comparison of quantitative data between control and experimental groups. Analyses were conducted using SAS v9.4 (Cary, NC) and all p-values are two-sided.

Animal experiments: All experiments were reviewed and approved by the RPCI IACUC. Mice were maintained in the Laboratory Animal Shared Resource with controlled air, light, and temperature conditions, and fed ad libitum with free access to water. NIH Swiss and C57BI/6J mice were purchased from The Jackson Laboratory.

For the analysis of gene expression, groups of three mice (female, 6-8 weeks old) were treated intravenously with one dose of CBL0137 dissolved in 5\% dextrose using the tail vein. Control mice received an injection of $5 \%$ dextrose.

For the comparison of the efficacy of different doses of CBL0137, SCID mice (male, 6-8 weeks old) were inoculated in both flanks with $10^{6}$ HepG2 cells in PBS. When tumors reach $\sim 50 \mathrm{~mm}^{3}$, mice were randomized into four groups $(n=5)$. Treatment was administered intravenously once a week. 


\section{Results \\ Treatment with CBL0137 changes transcription of genes in FACT-positive and -negative tissues}

The effect of CBL0137 on gene expression may be due to its binding to DNA and the unfolding of chromatin or due to the functional inhibition of FACT. To detect the potential FACTindependent effects of CBL0137, we sought to compare gene expression profiles in FACTpositive and -negative cells before and after CBL0137 treatment. All tumor and non-tumor cell lines tested to date express FACT subunits at different levels. The suppression of FACT expression with shRNA resulted in either partial reduction of FACT expression or complete knockdown of FACT in only a fraction of cells, which were quickly overgrown by FACT-positive cells (Carter, Murray et al., 2015, Dermawan, Hitomi et al., 2016, Safina, Garcia et al., 2013). To overcome this problem, we tested the effect of CBL0137 in vivo in tissues that either naturally express FACT or not. Liver and lung were selected as FACT-negative, and spleen and testis were used as FACT-positive tissues ((Garcia, Fleyshman et al., 2011) and Fig. 1A). Gene expression in these tissues was compared in mice treated with different doses of CBL0137 24 hours before organ collection. The three doses used represented different degrees of anticancer activity (weak, intermediate, and strong) with $90 \mathrm{mg} / \mathrm{kg}$ being close to the maximal tolerable dose (Fig.S1A).

Hybridization analysis using mouse Illumina BeadChip array showed that all samples were clustered according to their tissue of origin and dose of CBL0137 (Fig.S1B). The liver and spleen samples from the vehicle- or $30 \mathrm{mg} / \mathrm{kg}$ CBL0137-treated mice were grouped together, suggesting little or no effect of this dose on gene expression in the tested organs (Fig.S1B). Samples from mice treated with 60 and $90 \mathrm{mg} / \mathrm{kg}$ CBL0137 were also grouped together (spleen, testis) or close to each other (liver, lung), demonstrating a minimal difference between these doses. Surprisingly, very few genes changed expression in the testis (FACT-positive organ (Fig.S1C), which may be due to either limited accumulation of the drug in testis as the result of the blood-testis barrier ("Sertoli cell barrier" (Mruk \& Cheng, 2015) or the specific chromatin structure in this organ (Wu \& Chu, 2008). Maximal changes were observed in the FACT-positive spleen followed by lung and liver (FACT-negative organs) (Fig.S1C). The changes in gene expression caused by CBL0137 in these FACT-negative tissues suggest a FACT-independent mechanism.

There was almost no overlap in genes downregulated in response to CBL0137 among different organs (Fig. 1B, Supplemental Tables S1-S6). However, one gene, Ifit3, was upregulated in all organs (Fig.1C, D). Many transcripts in two or three organs increased similarly in a dosedependent manner in response to CBL0137 (Fig.1C, D), suggesting that there may be a common pathway(s) induced by CBL0137 independently of FACT. To identify this pathway(s), we performed gene set enrichment analysis (GSEA) using the Molecular Signature Database (Broad Institute). The interferon (IFN) signaling pathway was upregulated in response to doses above $30 \mathrm{mg} / \mathrm{kg}$ in all organs except testis, which was not analyzed due to the low number of upregulated genes (Fig.2A and Supplemental Tables S1-6). The same pathway was ranked first when the list of genes that were upregulated in response to CBL0137 in two or more organs was analyzed (Fig.2B). The transcription factors that regulate genes elevated in response to CBL0137 are Stat1, Irf1, Irf8 and Irf7 (Fig.2C). Part of the upregulated genes were targets of Sp1 in lung and p53 in the spleen (Fig.S3). This analysis suggested that CBL0137 treatment leads to the activation of the IFN response in all tissues independently of FACT expression, while p53 was activated only in the FACT-positive spleen, as expected (Gasparian et al., 2011).

\section{CBL0137 causes rapid and robust IFN response in mouse tissues}


We have shown previously that CBL0137 inhibits NF-kappaB via a FACT-dependent mechanism (Gasparian et al., 2011). Therefore, the activation of the IFN response was an unexpected finding, because the two pathways, NF-kappaB and IFN, have multiple common inducers and regulators (reviewed in (Pfeffer, 2011)). Hence, we confirmed the microarray data using different approaches. We observed an increase in the liver, lung, and spleen of the mRNA level of Irf7, a transcription factor whose expression is induced by IFN (Wathelet, Lin et al., 1998), following treatment with greater than $30 \mathrm{mg} / \mathrm{kg} \mathrm{CBL0137} \mathrm{(Fig.3A} \mathrm{and} \mathrm{S4A).} \mathrm{The} \mathrm{same}$ trend was observed in testis, but it did not reach statistical significance. Activation of the IFN response was confirmed using a second mouse strain by RT-PCR detection of an expanded set of IFN-inducible mRNAs, and at the protein level in spleen using an antibody to ISG49, the protein encoded by Ifit3 gene (Fig.3B, C, and S4B).

There are multiple known inducers of the IFN response, among which are components of viruses (e.g., dsRNA, cytoplasmic DNA), cytokines, DNA damage, and demethylation of genomic DNA (reviewed in (Silin, Lyubomska et al., 2009)). Based on the literature, the kinetics of the IFN response are different depending on the inducer, with viral components and cytokines being the quickest (minutes - several hours (Silin et al., 2009)), followed by DNA damage (1648 hours (Brzostek-Racine, Gordon et al., 2011)), and demethylating agents (>48 hours (Leonova et al., 2013)). To compare the effect of CBL0137 vis-à-vis these stimuli, we assessed the kinetics of induction of the IFN response after CBL0137 treatment. We first measured Irf7 mRNA in the spleen and lung of mice treated with three doses of CBL0137 for 24, 48, or 96 hours before organ collection. The peak of induction was already seen at 24 hours following treatment with either 60 or $90 \mathrm{mg} / \mathrm{kg} \mathrm{CBL0137,} \mathrm{while} 30 \mathrm{mg} / \mathrm{kg}$ showed slower kinetics (Fig. 3D, $\mathrm{E}$, and Fig.S5A, B). Increased levels of two other IFN responsive genes, Isg15 and Usp18, were detected as early as six hours post-treatment with $90 \mathrm{mg} / \mathrm{kg}$ CBL0137 and reached a peak at 12 hours, which then gradually declined (Fig.3F, G, and Fig.S5C). Similar kinetics were observed at the protein level (Fig.3H). Thus, the CBL0137-induced IFN response is faster than that reported with other small molecules and is closer to the response observed with biologicals.

\section{Increased expression of IFN-responsive genes induced by CBL0137 is dependent on IFN signaling}

Experiments with mice demonstrated that CBL0137 caused a rapid and robust induction of the IFN response in all tissues of mice that were tested. To investigate the mechanism of this phenomenon, we modeled this effect in vitro using normal and tumor cells (mouse and human). We detected an increase in mRNA and protein levels of IFN-inducible genes in both human and mouse fibroblasts (Fig.4A-C), but not in tumor cells of mouse or human origin (data not shown). Since different components of the IFN response are frequently inactivated in tumors (Kulaeva, Draghici et al., 2003), we employed a reporter assay that detected an IFN response through the activation of a consensus IFN-sensitive response element (ISRE), which drove the expression of mCherry (Imam, Ackrill et al., 1990). Polyinosinic-polycytidylic acid (poly(l:C)), a synthetic analog of double-stranded RNA (dsRNA), was used as a positive control for reporter activity. Using this assay, we observed that CBL0137 also induces an IFN response in both mouse and human tumor cells (Fig.4 D, E).

The next step towards the mechanism of CBL0137-activated IFN response was to establish whether this was, in fact, a response to IFNs, i.e. was there an increase in the IFNs level after CBL0137 treatment. However, our attempts to detect IFNs (alpha, beta or gamma) in the plasma of mice treated with CBL0137 or in cell culture medium failed, which may be due to the short half-life, low levels of IFNs even after induction, or both. To overcome this limitation and to test whether the induction of IFN responsive transcription after CBL0137 treatment was due to IFNs, we used cells with different components of the IFN signaling pathway inactivated, such as 
MEF from mice with a knockout of either the type I IFN receptor (Ifnar) or Irf1, or MEF with shRNA to Irf7 (transcription factors controlling the expression of IFN-responsive genes in response to IFN). We also used p53 -/- MEF since we have shown previously that the absence of p53 increases IFN signaling in response to dsRNA (Leonova et al., 2013). A deficiency in either Ifnar and Irf7 reduced or eliminated the induction of Ifit3 expression after CBL0137, respectively. In contrast, the loss of p53 stimulated the response. There was no effect of Irf1 knockout (Fig.5A). Similar results were obtained in vivo using spleens from Ifnar-/-, Irf7-/- or p53-/- mice treated with CBL0137 (Fig.5B).

\section{CBL0137 treatment leads to transcription of repetitive heterochromatic genomic regions}

A known trigger of the IFN response is a viral infection. There are several ways by which cells can detect viral invasion. First, viral dsRNA can be detected by several intra-cellular receptors, such as TLR3, 7 or 8, RIG1, and MDA5 (reviewed in (Unterholzner, 2013)). Additionally, the presence of DNA in the cytoplasm or non-B DNA, such as left-handed Z-DNA, found in some viruses (Nordheim \& Rich, 1983) can also be recognized by a cell as a viral infection. In the latter case, the IFN response is activated via Z-DNA-binding protein 1 (ZBP1), also known as the DNA-dependent activator of IFN (DAI) (Takaoka, Wang et al., 2007). Importantly, we have recently shown that high doses of CBL0137 caused disassembly of nucleosomes in cells, which led to the extensive negative supercoiling of DNA and a transition from B-DNA into left-handed Z-DNA (Fleyshman, Prendergast et al., 2017). Although this effect was observed at significantly higher CBL0137 concentrations $(>2.5 \mu \mathrm{M})$ than that which induced an IFN response, we investigated whether the effect of CBL0137 on nucleosomes could be responsible for its effect on the IFN response. To do this, we deleted the ZBP1 gene from HeLa and HT1080 cells using CRISP/Cas9 recombinase and two human ZBP1 gRNAs. The loss of ZBP1 expression was confirmed by RT-PCR (Fig. S6A). We compared the effect of CBL0137 on ISRE-mCherry reporter activity in these cells to wild-type cells and cells transduced with control gRNA and observed no change in the induction of the reporter activity 48 hours after CBL0137 treatment (Fig.S6B). There was also no Z-DNA present in the cells treated with CBL0137 doses that caused a robust IFN response as judged by the absence of staining with Z-DNA antibodies (Fig.S6C).

We next determined whether dsRNA-induced an IFN response in CBL0137-treated cells. Using an antibody to dsRNA (Targett-Adams, Boulant et al., 2008), we observed increased staining in CBL0137-treated cells (Fig. 6A, B). One potential endogenous source of dsRNA may be from the transcription of repetitive elements, such as endogenous retroviruses, centromeric, or pericentromeric repeats (Leonova et al., 2013). Transcription of these elements may be enhanced as a result of nucleosome destabilization and chromatin unfolding caused by CBL0137. Short Interspersed Nuclear Element (SINE) retrotransposons constitute one of the main components of the genomic repetitive fraction (Kramerov \& Vassetzky, 2011). Hence, we first tested whether transcription of B1 SINE is increased upon CBL0137 treatment using northern blotting. In samples of untreated MEFs, binding of the B1 probe was detected for a number of different length transcripts, possibly due to the presence of B1 repeats within the introns of multiple mRNAs. After CBL0137 treatment, a single lower molecular weight band appeared that was strongly bound by the B1 probe and was similar in size and abundance to the band in cells treated with the positive control (5-aza-cytidine (5-aza)) (Fig. 6C). To determine whether other transcripts that can form dsRNAs appear in cells treated with CBL0137, we performed RNA-sequencing (RNA-seq) analysis using total RNA from wild-type and p53-/- MEF treated with CBL0137 in vitro or lungs from mice collected 24 hours after treatment with 60 $\mathrm{mg} / \mathrm{kg}$ CBL0137 in vivo. This analysis demonstrated a significant increase in the number of transcripts corresponding to several classes of endogenous viruses as well as GSAT (pericentromeric) and SATMIN (centromeric) repeats in cells (Fig.6D and Supplemental Table 
S7). These data suggest that treatment with CBL0137 leads to the activation of the transcription of heterochromatic regions, which are not or minimally transcribed under basal conditions.

\section{TRAIN occurs in response to nucleosome "opening"}

CBL0137 may induce transcription of genomic regions that are silenced at physiological conditions via several different mechanisms. Loss of FACT via c-trapping may lead to activation of silenced transcription since mutations of FACT subunits in yeast causes transcription from cryptic sites that are covered by nucleosomes in basal conditions (Mason \& Struhl, 2003), (Jamai, Puglisi et al., 2009). FACT is also important for chromatin assembly at centromeres (Okada, Okawa et al., 2009, Prendergast, Muller et al., 2016). We observed the induction of the IFN response in organs that lacked FACT (lung and liver). However, the absence of FACT in these tissues does not exclude the role of FACT in the prevention of the response. Nevertheless, it was clear that there are FACT-independent effects of CBL0137 on transcription.

Opening or disassembly of nucleosomes due to CBL0137 binding to DNA may increase accessibility of DNA to RNA Polymerase (RNAP) II. To see whether CBL0137 can induce transcription of a reporter silenced due to chromatin condensation, we used HeLa-TI cells (Poleshko et al., 2010, Shalginskikh et al., 2013), which contain an integrated avian sarcoma genome with a silenced green fluorescent protein (GFP) gene. Under basal conditions, GFP is expressed in very few cells. However, the opening of chromatin using the HDAC inhibitor trichostatin A (TSA) activates GFP expression in a significant proportion of cells (Fig.7A). An increase in the proportion of GFP-expressing cells was observed after CBL0137 treatment (Fig. 7A). Moreover, the effect of CBL0137 was faster than TSA, reaching a maximum in 12 hours, while after TSA, the peak GFP expression was reached at 36 hours.

Next, we tested whether chromatin opening by HDAC inhibition causes TRAIN. We treated MEF and HeLa-TI cells with TSA or CBL0137 and monitored the activation of IFN signaling by RTPCR in MEF or ISRE-mCherry reporter in Hela-TI cells (Fig. 7B, C). In MEF cells, both TSA and CBL0137 induced expression of Ifit3 and Irf7 genes (Fig.7B), while in HeLa-TI cells, the robust induction of ISRE reporter was evident only after CBL0137 treatment. TSA caused only a weak increase in ISRE reporter activity (1.5 folds versus $>5$ folds for CBL0137) only at the highest concentration (500 nM, Fig.7C) when evidence of toxicity was present. At the same time, the degree of activation of the silenced GFP in HeLa-TI cells was similar for TSA and CBL0137 (Fig.7C). Thus, TRAIN can be induced by different means of chromatin opening, but its magnitude depends on cell type.

Importantly, although GFP expression was increased by both agents, the mechanisms of chromatin opening were different for TSA and CBL0137. As expected, TSA treatment caused an increase in acetylated histone H3 levels, while CBL0137 decreased the amount of chromatin-bound histone H3 (Fig.7D). However, as we saw previously (Safina et al., 2017), substantial loss of core histones (i.e., chromatin disassembly) was observed with approximately $5 \mu \mathrm{M}$ CBL0137, which is much higher than the concentrations at which we observed TRAIN $(<1$ $\mu \mathrm{M}$, peak at $0.5 \mu \mathrm{M})$. We proposed that nucleosome "opening," i.e., the state of loose contact between the DNA and histone core without loss of histones from the core (proposed in the review (Zlatanova, Bishop et al., 2009)), is enough for the induction of TRAIN. Namely, no nucleosome disassembly or dissociation of nucleosome parts is needed. Although there is no clear definition of an opened and a closed nucleosome state, the closed nucleosome in cells is additionally "locked" by the linker histone H1 (Syed, Goutte-Gattat et al., 2010, Zhou, Feng et al., 2013). Thus, we investigated how the distribution of $\mathrm{H} 1$ is changed upon treatment with CBL0137 using imaging of live cells that express m-Cherry-tagged histone H1.5. CBL0137 treatment led to a redistribution of $\mathrm{H} 1.5$ from the chromatin to the nucleoli, similarly to the effect 
of CBL0137 on core histones (Safina et al., 2017) but this phenomenon was observed at a faster and at much lower CBL0137 concentrations (Fig.8A, B). TRAIN in CBL0137-treated cells was observed at the same concentration range as redistribution of histone $\mathrm{H} 1$ and before the disassembly of the nucleosome core, suggesting that nucleosome opening is sufficient to allow the transcription of heterochromatic regions in cells.

\section{TRAIN induced by CBL0137 impacts the tumor-preventive activity of CBL0137}

We have previously shown that administration of CBL0137 to tumor prone mice prior to tumor onset significantly reduced the incidence of cancer and diminished the occurrence of aggressive forms of breast cancer (Koman, Commane et al., 2012). We explained this effect by the fact that CBL0137 inhibited NF-kappaB and activated p53, both well-established mechanisms of cancer prevention (rev. in (Athar, Elmets et al., 2011) and (Lin, Bai et al., 2010)). However, activation of IFN may be an additional mechanism to eliminate transformed cells, because they are more sensitive to IFN-mediated apoptosis than normal cells (reviewed in (Parker, Rautela et al., 2016)). To test this hypothesis, we used p53-negative MEF (to eliminate the effect of p53 activation) with a functional or disabled IFN response via knockout of Ifnar (Picaud, Bardot et al., 2002). MEF cells have almost no basal NF-kappaB activity. Both cell types were transduced with a lentiviral construct for the expression of the mutant $\mathrm{H}$-Ras ${ }^{\mathrm{V} 12}$ oncogene. Forty-eight hours after lentiviral transduction, cells were treated with a low dose of CBL0137 for an additional 48 hours and then left to grow in drug-free medium. After ten days, the number of transformed foci was significantly reduced in cells treated with CBL0137 compared to untreated cells, but only if the cells had functional INF receptor (Ifnar $+/+$, Fig.9). Thus, TRAIN may be an additional mechanism by which CBL0137 exerts its anti-tumor and tumor preventive effect.

\section{Discussion}

Our study describes the consequences of chromatin destabilization caused by small molecule binding to DNA. CBL0137 was identified in a cell-based screen, and some of its effects, such as activation of p53 and inhibition of NF-kappaB, functional inactivation of FACT, and higher toxicity to tumor than normal cells, were already described (Gasparian et al., 2011), (Barone, Burkhart et al., 2017, Carter et al., 2015, Dermawan et al., 2016). However, recently we demonstrated that binding of CBL0137 to DNA destabilizes nucleosomes in vitro and in vivo, leading to histone eviction and chromatin decondensation in cells (Safina et al., 2017). Since CBL0137 does not cause chemical DNA modifications and has no effect on transcription and replication of naked DNA in vitro at the concentrations used in this study, this creates a unique situation to assess how chromatin "damage" influences transcription.

First, we would like to define chromatin "damage" as a change in the original chromatin composition that is artificially induced by a drug. In the case of CBL0137, this chromatin "damage" occurs most probably in a few continuous phases (Fig.10). At lower concentrations of CBL0137 $(<1 \mu \mathrm{M}$ in cells), the nucleosome "opens," loses the linker histone $\mathrm{H} 1$ without dissociation or loss of core histones. At higher CBL0137 concentrations (1-5 $\mu \mathrm{M})$, dimer detachment occurs with occasional loss of core histones. We clearly saw this stage in vitro as the appearance of hexasomes (Safina et al., 2017). At CBL0137 concentrations greater than $5 \mu \mathrm{M}$, the nucleosome is disassembled, and core histones are evicted from the chromatin. This sequence of events is in line with the reversibility of the toxic effects of CBL0137. Indeed, after a short incubation with $<1 \mu \mathrm{M}$ CBL0137, the drug can be washed from the cells with almost no harm to the cells; cells incubated with 1-3 $\mu \mathrm{M}$ CBL0137 for no more than one hour survive with some loss of viability. However, treatment with $>5 \mu \mathrm{M}$ CBL0137 for more than 15 minutes leads to complete cell death, which is in line with the complete disassembly of chromatin. An 
important and completely unknown question is what causes cell death upon loss of chromatin integrity.

Other cellular "responses" to CBL0137 treatment are also aligned with a gradual change in nucleosome organization. The first cellular factor that we found "reacting" to the problems with chromatin packaging in CBL0137-treated cells was histone chaperone FACT, which underwent c-trapping in response to nucleosome disassembly. It was shown that human FACT cannot bind and uncoil a "closed" nucleosome (Tsunaka, Fujiwara et al., 2016, Valieva, Gerasimova et al., 2017) (Fig.10). However, nucleosome opening most probably allows FACT to invade the nucleosome and bind the $\mathrm{H} 3 / \mathrm{H} 4$ tetramer via the middle domain of SPT16 and the $\mathrm{H} 2 \mathrm{~A} / \mathrm{H} 2 \mathrm{~B}$ dimer via the c-terminal portions of both subunits (Belotserkovskaya et al., 2003, Kemble, McCullough et al., 2015, Tsunaka et al., 2016, Winkler \& Luger, 2011). In cells, we see this as SPT16-mediated "n (nucleosome)-trapping," which is observed at 0.3-1 $\mu \mathrm{M}$ CBL0137. At CBL0137 concentrations greater than $3 \mu \mathrm{M}$, significant negative supercoiling, as a result of nucleosome disassembly, caused base-unpairing of DNA and the transition of B-DNA into lefthanded Z-form DNA, which is bound by FACT via the c-terminal intrinsically disordered domain of SSRP1 subunit (Safina et al., 2017). FACT has a plethora of activities related to transcription (rev. in (Reinberg \& Sims, 2006)). Therefore, many CBL0137 effects on transcription might be explained by the functional inactivation of FACT. However, we suspected that opening of chromatin might have consequences independent on FACT.

The most prominent and uniform change observed in the presence and absence of FACT was activation of the IFN response in all tested organs and cells at both the mRNA and protein levels. The induction of IFN-sensitive genes (ISG) has a bell-shaped curve, with a maximum increase at a CBL0137 concentration of approximately $0.5 \mu \mathrm{M}$, which corresponds to nucleosome "opening" followed by the inhibition of transcription at concentrations greater than 1 $\mu \mathrm{M}$, when nucleosome disassembly starts. We believe that IFN is activated in response to the dsRNA formed due to the increased transcription from normally silenced heterochromatic regions. There was a report that proposed the role of histone $\mathrm{H} 1$ in the silencing of ISGs where knockdown of the $\mathrm{H} 1$ chaperone TAF1 in cells resulted in $\mathrm{H} 1$ loss from ISG promoters and activation of their transcription (Kadota \& Nagata, 2014). However, the set of data in that report does not exclude the role of general chromatin decondensation due to the reduction of $\mathrm{H} 1$ deposition in heterochromatin. We showed that in the case of CBL0137, transcription of ISGs is abrogated if the IFN signaling pathway is disabled (e.g., Ifnar-/- cells and mice), suggesting that there is no direct effect of CBL0137 on the promoters of ISGs. If we assume that IFN is activated in response to increased transcription of repetitive heterochromatin genomic regions, then the puzzling and intriguing question is why nucleosome "opening" is accompanied by selective activation of transcription of these elements, but not most genes, while nucleosome disassembly leads to the inhibition of transcription genome-wide. We propose that displacement of histone $\mathrm{H} 1$ may make heterochromatin accessible for RNA polymerase, while accessibility of genomic regions not locked with $\mathrm{H} 1$ does not change. The inhibition may be explained by a direct effect of higher concentrations of CBL0137, bound to DNA, on RNA polymerase activity, but this requires further investigation.

Importantly, the anti-cancer effect in mice is seen at concentrations that activate the IFN response, suggesting that chromatin opening without chromatin disassembly is enough to cause an anti-cancer effect in vivo. Activation of the IFN response by CBL0137 also creates an opportunity to use IFN-responsive factors as pharmacodynamic markers of curaxin activity in the clinic, since many of these factors are secreted and were detected in the plasma of mice.

Thus, curaxins, compounds with established anti-cancer activity in multiple preclinical models, may also be used as a tool to affect chromatin organization and folding globally in cells and 
animals to study the consequences of an abrupt loss of epigenetic regulation in vivo. Potentially, this property of curaxins may be useful for reprogramming and other types of therapeutic epigenetic manipulations.

One more important aspect of this study was the expansion of the set of situations when the TRAIN response occurs. Previously, we and others observed TRAIN upon loss of DNA methylation (Leonova et al., 2013), (Chiappinelli et al., 2015, Guryanova et al., 2016, Roulois et al., 2015), mostly in the case of p53 deficiency (Leonova et al., 2013). Here, we observed that general chromatin decondensation due to nucleosome opening is also accompanied by TRAIN with much less dependence on p53 status. Based on this data, we propose that TRAIN may be a more general response to the problems associated with chromatin packaging and the danger of the loss of epigenetic integrity. The stability of the cell differentiation status, which can still be easily detected even in Hela cells after more than 60 years in culture, is a long-standing puzzle. Theoretically, stability can be ensured either by the low rate of error in the replication of chromatin marks or by an auto-regulatory mechanism that eliminates cells with lost epigenetic information, similar to p53-dependent apoptosis in response to DNA damage. It is tempting to speculate that TRAIN may be such a mechanism, triggered by elevated expression of silenced repetitive genomic elements and executed by the IFN response, which is capable of killing cells. It is likely that this mechanism evolved in response to real viral threats, especially in the form of the expansion of endogenous retroviral elements. Eventually, this mechanism served as an epigenetic lock, which may be as beneficial to support the differentiation state, and limit cell plasticity and, therefore, the ability to transdifferentiate and regenerate organs and tissues. 


\section{References}

Athar M, Elmets CA, Kopelovich L (2011) Pharmacological activation of p53 in cancer cells. Curr Pharm Des 17: 631-9

Barone TA, Burkhart CA, Safina A, Haderski G, Gurova KV, Purmal AA, Gudkov AV, Plunkett RJ (2017) Anticancer drug candidate CBL0137, which inhibits histone chaperone FACT, is efficacious in preclinical orthotopic models of temozolomide-responsive and -resistant glioblastoma. Neuro Oncol 19: 186-196

Belotserkovskaya R, Oh S, Bondarenko VA, Orphanides G, Studitsky VM, Reinberg D (2003) FACT facilitates transcription-dependent nucleosome alteration. Science 301: 1090-3

Brzostek-Racine S, Gordon C, Van Scoy S, Reich NC (2011) The DNA damage response induces IFN. J Immunol 187: 5336-45

Campos El, Stafford JM, Reinberg D (2014) Epigenetic inheritance: histone bookmarks across generations. Trends Cell Biol 24: 664-74

Carter DR, Murray J, Cheung BB, Gamble L, Koach J, Tsang J, Sutton S, Kalla H, Syed S, Gifford AJ, Issaeva N, Biktasova A, Atmadibrata B, Sun Y, Sokolowski N, Ling D, Kim PY, Webber H, Clark A, Ruhle M et al. (2015) Therapeutic targeting of the MYC signal by inhibition of histone chaperone FACT in neuroblastoma. Sci Transl Med 7: 312ra176

Chiappinelli KB, Strissel PL, Desrichard A, Li H, Henke C, Akman B, Hein A, Rote NS, Cope LM, Snyder A, Makarov V, Budhu S, Slamon DJ, Wolchok JD, Pardoll DM, Beckmann MW, Zahnow CA, Merghoub T, Chan TA, Baylin SB et al. (2015) Inhibiting DNA Methylation Causes an Interferon Response in Cancer via dsRNA Including Endogenous Retroviruses. Cell 162: 974-86

Dermawan JK, Hitomi M, Silver DJ, Wu Q, Sandlesh P, Sloan AE, Purmal AA, Gurova KV, Rich JN, Lathia JD, Stark GR, Venere M (2016) Pharmacological Targeting of the Histone Chaperone Complex FACT Preferentially Eliminates Glioblastoma Stem Cells and Prolongs Survival in Preclinical Models.

Cancer Res 76: 2432-42

Ebrahimi B (2015) Reprogramming barriers and enhancers: strategies to enhance the efficiency and kinetics of induced pluripotency. Cell Regen (Lond) 4: 10

Fleyshman D, Prendergast L, Safina A, Paszkiewicz G, Commane M, Morgan K, Attwood K, Gurova $K$ (2017) Level of FACT defines the transcriptional landscape and aggressive phenotype of breast cancer cells. Oncotarget 8: 20525-20542

Garcia H, Fleyshman D, Kolesnikova K, Safina A, Commane M, Paszkiewicz G, Omelian A, Morrison C, Gurova K (2011) Expression of FACT in mammalian tissues suggests its role in maintaining of undifferentiated state of cells. Oncotarget 2: 783-96

Gariglio M, Ying GG, Hertel L, Gaboli M, Clerc RG, Landolfo S (1997) The high-mobility group protein T160 binds to both linear and cruciform DNA and mediates DNA bending as determined by ring closure. Exp Cell Res 236: 472-81

Gasparian AV, Burkhart CA, Purmal AA, Brodsky L, Pal M, Saranadasa M, Bosykh DA, Commane M, Guryanova OA, Pal S, Safina A, Sviridov S, Koman IE, Veith J, Komar AA, Gudkov AV, Gurova KV (2011) Curaxins: anticancer compounds that simultaneously suppress NF-kappaB and activate p53 by targeting FACT. Sci Transl Med 3: 95ra74

Guryanova OA, Shank K, Spitzer B, Luciani L, Koche RP, Garrett-Bakelman FE, Ganzel C, Durham BH, Mohanty A, Hoermann G, Rivera SA, Chramiec AG, Pronier E, Bastian L, Keller MD, Tovbin D, Loizou E, Weinstein AR, Gonzalez AR, Lieu YK et al. (2016) DNMT3A mutations promote anthracycline resistance in acute myeloid leukemia via impaired nucleosome remodeling. Nat Med 22: 1488-1495

Hussein SM, Nagy AA (2012) Progress made in the reprogramming field: new factors, new strategies and a new outlook. Curr Opin Genet Dev 22: 435-43 
Imam AM, Ackrill AM, Dale TC, Kerr IM, Stark GR (1990) Transcription factors induced by interferons alpha and gamma. Nucleic Acids Res 18: 6573-80

Jamai A, Puglisi A, Strubin M (2009) Histone chaperone spt16 promotes redeposition of the original h3-h4 histones evicted by elongating RNA polymerase. Mol Cell 35: 377-83

Kadota S, Nagata K (2014) Silencing of IFN-stimulated gene transcription is regulated by histone $\mathrm{H} 1$ and its chaperone TAF-I. Nucleic Acids Res 42: 7642-53

Kapitonov VV, Jurka J (2008) A universal classification of eukaryotic transposable elements implemented in Repbase. Nat Rev Genet 9: 411-2; author reply 414

Kemble DJ, McCullough LL, Whitby FG, Formosa T, Hill CP (2015) FACT Disrupts Nucleosome Structure by Binding H2A-H2B with Conserved Peptide Motifs. Mol Cell 60: 294-306

Koman IE, Commane M, Paszkiewicz G, Hoonjan B, Pal S, Safina A, Toshkov I, Purmal AA, Wang D, Liu S, Morrison C, Gudkov AV, Gurova KV (2012) Targeting FACT complex suppresses mammary tumorigenesis in Her2/neu transgenic mice. Cancer Prev Res (Phila) 5: 1025-35

Kramerov DA, Vassetzky NS (2011) SINEs. Wiley Interdiscip Rev RNA 2: 772-86

Krohn NM, Stemmer C, Fojan P, Grimm R, Grasser KD (2003) Protein kinase CK2 phosphorylates the high mobility group domain protein SSRP1, inducing the recognition of UV-damaged DNA. J Biol Chem 278: 12710-5

Kulaeva OI, Draghici S, Tang L, Kraniak JM, Land SJ, Tainsky MA (2003) Epigenetic silencing of multiple interferon pathway genes after cellular immortalization. Oncogene 22: 4118-27

Leonova KI, Brodsky L, Lipchick B, Pal M, Novototskaya L, Chenchik AA, Sen GC, Komarova EA, Gudkov AV (2013) p53 cooperates with DNA methylation and a suicidal interferon response to maintain epigenetic silencing of repeats and noncoding RNAs. Proc Natl Acad Sci U S A 110: E89-98

Lin Y, Bai L, Chen W, Xu S (2010) The NF-kappaB activation pathways, emerging molecular targets for cancer prevention and therapy. Expert Opin Ther Targets 14: 45-55

Luger K, Mader AW, Richmond RK, Sargent DF, Richmond TJ (1997) Crystal structure of the nucleosome core particle at 2.8 A resolution. Nature 389: 251-60

Mason PB, Struhl K (2003) The FACT complex travels with elongating RNA polymerase II and is important for the fidelity of transcriptional initiation in vivo. Mol Cell Biol 23: 8323-33

Miller KM (2010) Advances in understanding genome maintenance. Genome Biol 11: 301

Miska EA, Ferguson-Smith AC (2016) Transgenerational inheritance: Models and mechanisms of non-DNA sequence-based inheritance. Science 354: 59-63

Mruk DD, Cheng CY (2015) The Mammalian Blood-Testis Barrier: Its Biology and Regulation.

Endocr Rev 36: 564-91

Nordheim A, Rich A (1983) Negatively supercoiled simian virus 40 DNA contains Z-DNA segments within transcriptional enhancer sequences. Nature 303: 674-9

Okada M, Okawa K, Isobe T, Fukagawa T (2009) CENP-H-containing complex facilitates centromere deposition of CENP-A in cooperation with FACT and CHD1. Mol Biol Cell 20: 3986-95

Parker BS, Rautela J, Hertzog PJ (2016) Antitumour actions of interferons: implications for cancer therapy. Nat Rev Cancer 16: 131-44

Patro R, Mount SM, Kingsford C (2014) Sailfish enables alignment-free isoform quantification from RNA-seq reads using lightweight algorithms. Nat Biotechnol 32: 462-4

Pfeffer LM (2011) The role of nuclear factor kappaB in the interferon response. J Interferon Cytokine Res 31: 553-9

Picaud S, Bardot B, De Maeyer E, Seif I (2002) Enhanced tumor development in mice lacking a functional type I interferon receptor. J Interferon Cytokine Res 22: 457-62

Poleshko A, Einarson MB, Shalginskikh N, Zhang R, Adams PD, Skalka AM, Katz RA (2010) Identification of a functional network of human epigenetic silencing factors. J Biol Chem 285: 422-33 
Prendergast L, Muller S, Liu Y, Huang H, Dingli F, Loew D, Vassias I, Patel DJ, Sullivan KF, Almouzni G (2016) The CENP-T/-W complex is a binding partner of the histone chaperone FACT. Genes Dev 30: 1313-26

Qian HR, Huang S (2005) Comparison of false discovery rate methods in identifying genes with differential expression. Genomics 86: 495-503

Reinberg D, Sims RJ, 3rd (2006) de FACTo nucleosome dynamics. J Biol Chem 281: 23297-301

Roulois D, Loo Yau H, Singhania R, Wang Y, Danesh A, Shen SY, Han H, Liang G, Jones PA, Pugh TJ, O'Brien C, De Carvalho DD (2015) DNA-Demethylating Agents Target Colorectal Cancer Cells by Inducing Viral Mimicry by Endogenous Transcripts. Cell 162: 961-73

Safina A, Cheney P, Pal M, Brodsky L, Ivanov A, Kirsanov K, Lesovaya E, Naberezhnov D, Nesher E, Koman I, Wang D, Wang J, Yakubovskaya M, Winkler D, Gurova K (2017) FACT is a sensor of DNA torsional stress in eukaryotic cells. Nucleic Acids Res 45: 1925-1945

Safina A, Garcia H, Commane M, Guryanova O, Degan S, Kolesnikova K, Gurova KV (2013) Complex mutual regulation of facilitates chromatin transcription (FACT) subunits on both mRNA and protein levels in human cells. Cell Cycle 12: 2423-34

Shalginskikh N, Poleshko A, Skalka AM, Katz RA (2013) Retroviral DNA methylation and epigenetic repression are mediated by the antiviral host protein Daxx. J Virol 87: 2137-50

Silin DS, Lyubomska OV, Ershov FI, Frolov VM, Kutsyna GA (2009) Synthetic and natural immunomodulators acting as interferon inducers. Curr Pharm Des 15: 1238-47

Syed SH, Goutte-Gattat D, Becker N, Meyer S, Shukla MS, Hayes JJ, Everaers R, Angelov D, Bednar J, Dimitrov S (2010) Single-base resolution mapping of H1-nucleosome interactions and 3D organization of the nucleosome. Proc Natl Acad Sci U S A 107: 9620-5

Takaoka A, Wang Z, Choi MK, Yanai H, Negishi H, Ban T, Lu Y, Miyagishi M, Kodama T, Honda K, Ohba Y, Taniguchi T (2007) DAI (DLM-1/ZBP1) is a cytosolic DNA sensor and an activator of innate immune response. Nature 448: 501-5

Targett-Adams P, Boulant S, McLauchlan J (2008) Visualization of double-stranded RNA in cells supporting hepatitis $C$ virus RNA replication. J Virol 82: 2182-95

Tsunaka Y, Fujiwara Y, Oyama T, Hirose S, Morikawa K (2016) Integrated molecular mechanism directing nucleosome reorganization by human FACT. Genes Dev 30: 673-86

Unterholzner L (2013) The interferon response to intracellular DNA: why so many receptors? Immunobiology 218: 1312-21

Valieva ME, Armeev GA, Kudryashova KS, Gerasimova NS, Shaytan AK, Kulaeva OI, McCullough LL, Formosa T, Georgiev PG, Kirpichnikov MP, Studitsky VM, Feofanov AV (2016) Large-scale ATPindependent nucleosome unfolding by a histone chaperone. Nat Struct Mol Biol 23: 1111-1116

Valieva ME, Gerasimova NS, Kudryashova KS, Kozlova AL, Kirpichnikov MP, Hu Q, Botuyan MV, Mer G, Feofanov AV, Studitsky VM (2017) Stabilization of Nucleosomes by Histone Tails and by FACT Revealed by spFRET Microscopy. Cancers (Basel) 9

Wagner GP, Kin K, Lynch VJ (2013) A model based criterion for gene expression calls using RNAseq data. Theory Biosci 132: 159-64

Wang J, Lindahl T (2016) Maintenance of Genome Stability. Genomics Proteomics Bioinformatics 14: $119-21$

Wathelet MG, Lin CH, Parekh BS, Ronco LV, Howley PM, Maniatis T (1998) Virus infection induces the assembly of coordinately activated transcription factors on the IFN-beta enhancer in vivo. Mol Cell 1: 507-18

Winkler DD, Luger K (2011) The histone chaperone FACT: structural insights and mechanisms for nucleosome reorganization. J Biol Chem 286: 18369-74

Wu TF, Chu DS (2008) Sperm chromatin: fertile grounds for proteomic discovery of clinical tools. Mol Cell Proteomics 7: 1876-86 
Yarnell AT, Oh S, Reinberg D, Lippard SJ (2001) Interaction of FACT, SSRP1, and the high mobility group (HMG) domain of SSRP1 with DNA damaged by the anticancer drug cisplatin. J Biol Chem 276: 25736-41

Zhou BR, Feng H, Kato H, Dai L, Yang Y, Zhou Y, Bai Y (2013) Structural insights into the histone H1-nucleosome complex. Proc Natl Acad Sci U S A 110: 19390-5

Zlatanova J, Bishop TC, Victor JM, Jackson V, van Holde K (2009) The nucleosome family: dynamic and growing. Structure 17: 160-71 
A

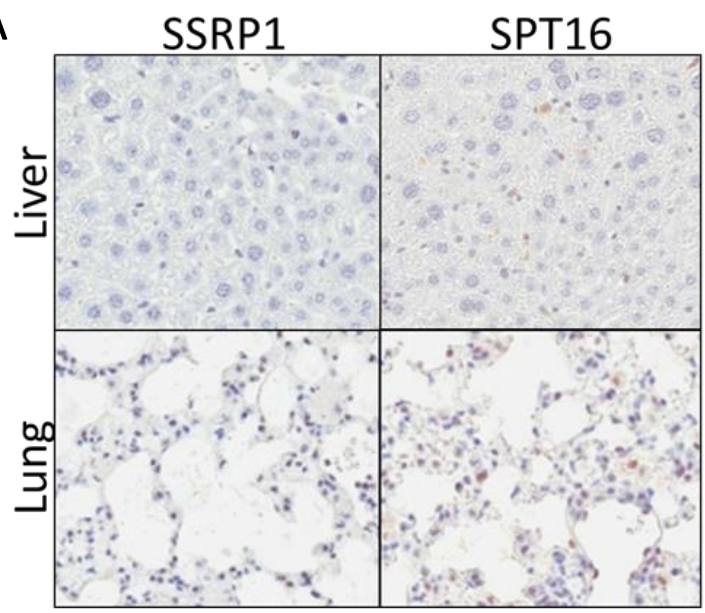

B

D

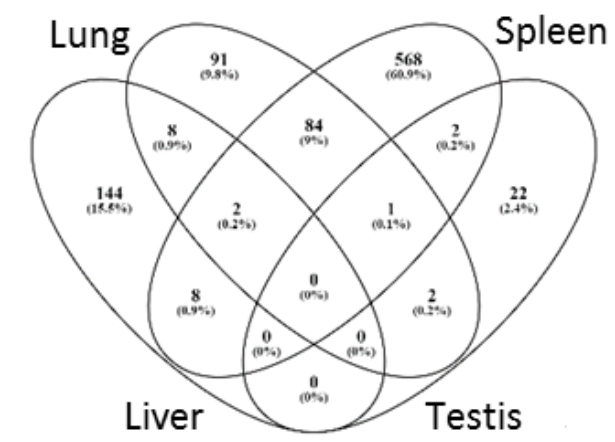

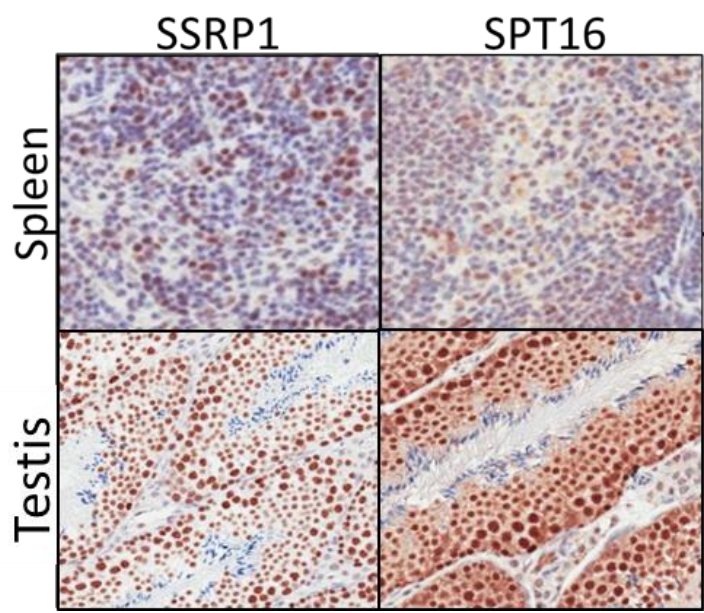

C

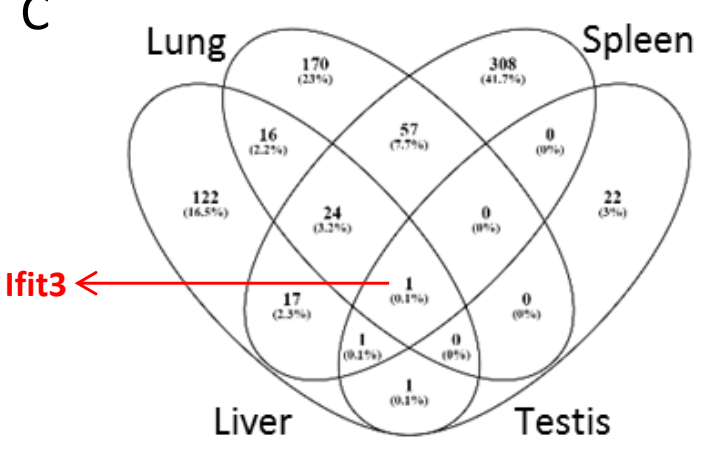

Liver
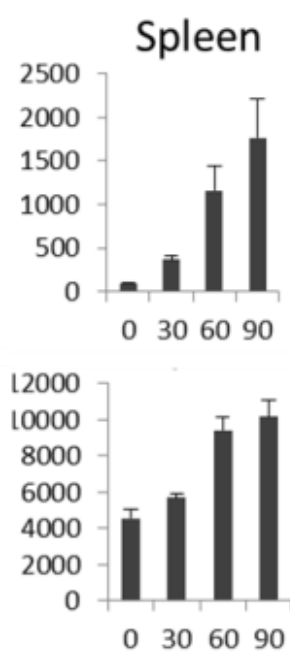
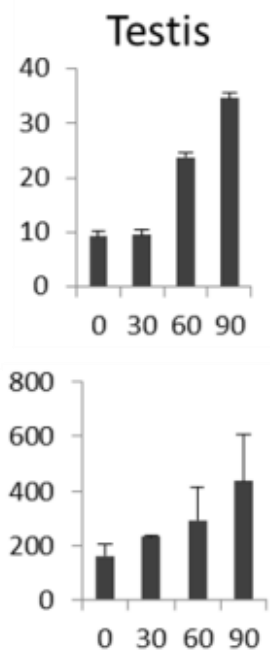

CBL0137 (mg/kg)

Figure 1. Effect of CBL0137 on transcription of genes in FACT positive and negative mouse tissues. A. IHC staining with SSRP1 antibody of liver and lung tissues with no detectable SSRP1 and spleen and testis expressing SSRP1. B, C. Venn diagrams of the lists of genes for which expression was downregulated (B) or upregulated (C) in response to CBL0137. D. Dose-dependent upregulation of Ifit3 and Ifitm3 mRNAs in different organs. Mean normalized value of microarray hybridization signal + - SD. 
bioRxiv preprint doi: https://doi.org/10.1101/142471; this version posted June 28,2017 . The copyright holder for this preprint (which was not certified by peer review) is the author/funder, who has granted bioRxiv a license to display the preprint in perpetuity. It is made available under aCC-BY-NC-ND 4.0 International license.

A

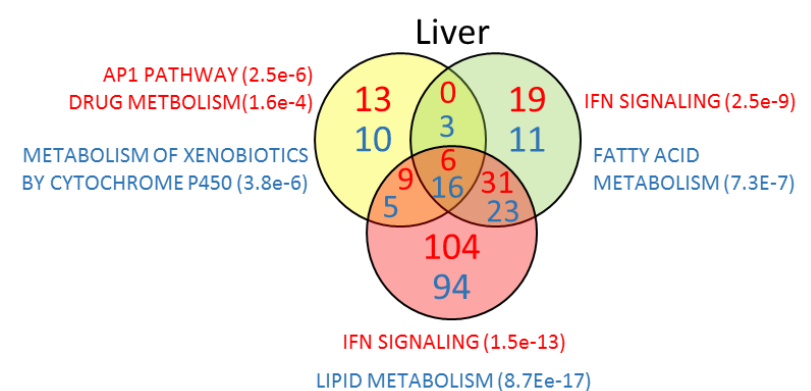

$30 \mathrm{mg} / \mathrm{kg}$

$60 \mathrm{mg} / \mathrm{kg}$

$90 \mathrm{mg} / \mathrm{kg}$

Spleen

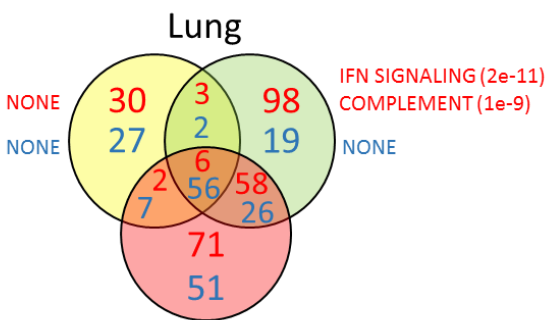

IFN SIGNALING (1.5e-20)

NABA MATRISOME(3.4Ee-5)

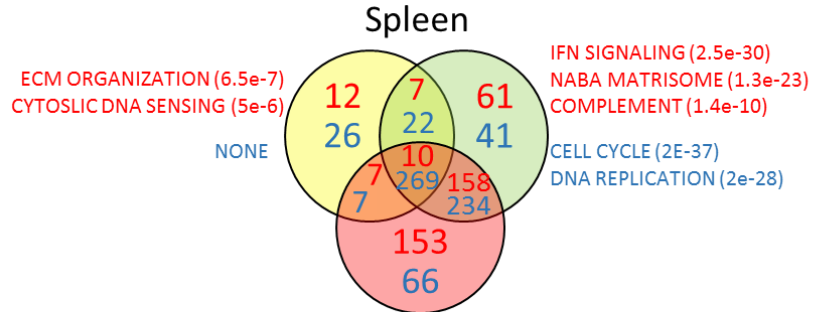

IFN SIGNALING (4.4e-28)

NABA MATRISOME (6e-25)

CELL CYCLE (1.3Ee-40)

B

DNA REPLICATION (6.4e-31)

\begin{tabular}{|c|c|c|c|c|c|}
\hline Gene Set Name & $\begin{array}{c}\text { No Genes in } \\
\text { Gene Set (K) }\end{array}$ & $\begin{array}{c}\text { No Genes in } \\
\text { Overlap (k) }\end{array}$ & k/K & P-value & $\begin{array}{c}\text { FDR q- } \\
\text { value }\end{array}$ \\
\hline REACTOME_INTERFERON_ALPHA_BETA_SIGNALING & 64 & 14 & 0.2188 & $1.44 \mathrm{E}-26$ & $1.91 \mathrm{E}-23$ \\
\hline REACTOME_INTERFERON_SIGNALING & 159 & 16 & 0.1006 & $1.76 \mathrm{E}-24$ & $1.17 \mathrm{E}-21$ \\
\hline REACTOME_CYTOKINE_SIGNALING_IN_IMMUNE_SYSTEM & 270 & 17 & 0.063 & $2.00 \mathrm{E}-22$ & $8.84 \mathrm{E}-20$ \\
\hline REACTOME_IMMUNE_SYSTEM & 933 & 23 & 0.0247 & $5.60 \mathrm{E}-21$ & $1.86 \mathrm{E}-18$ \\
\hline REACTOME_INTERFERON_GAMMA_SIGNALING & 63 & 6 & 0.0952 & $1.05 \mathrm{E}-09$ & $2.80 \mathrm{E}-07$ \\
\hline REACTOME_REGULATION_OF_IFNA_SIGNALING & 24 & 4 & 0.1667 & $7.15 \mathrm{E}-08$ & $1.58 \mathrm{E}-05$ \\
\hline ST_TYPE_IINTERFERON_PATHWAY & 9 & 3 & 0.3333 & $3.62 \mathrm{E}-07$ & $5.81 \mathrm{E}-05$ \\
\hline REACTOME_INNATE_IMMUNE_SYSTEM & 279 & 7 & 0.0251 & $4.31 \mathrm{E}-07$ & $5.81 \mathrm{E}-05$ \\
\hline PID_IL23_PATHWAY_PSE-0 & 37 & 4 & 0.1081 & $4.38 \mathrm{E}-07$ & $5.81 \mathrm{E}-05$ \\
\hline
\end{tabular}

C

\begin{tabular}{|c|c|c|c|c|c|c|}
\hline Gene Set Name & $\begin{array}{c}\text { No Genes in Gene } \\
\text { Set (K) }\end{array}$ & Description & $\begin{array}{c}\text { \# Genes in } \\
\text { Overlap (k) }\end{array}$ & k/K & P-value & FDR q-value \\
\hline V\$ISRE_01 & 247 & STAT1 & 10 & 0.0405 & $1.17 \mathrm{E}-11$ & $7.21 \mathrm{E}-09$ \\
\hline STTTCRNTTT_V\$IRF_Q6 & 188 & Unknown & 8 & 0.0426 & $1.00 \mathrm{E}-09$ & $3.09 \mathrm{E}-07$ \\
\hline V\$IRF_Q6 & 242 & IRF1 & 8 & 0.0331 & $7.29 \mathrm{E}-09$ & $1.36 \mathrm{E}-06$ \\
\hline V\$ICSBP_Q6 & 248 & IRF8 & 8 & 0.0323 & $8.83 \mathrm{E}-09$ & $1.36 \mathrm{E}-06$ \\
\hline V\$IRF7_01 & 252 & IRF7 & 6 & 0.0238 & $4.06 \mathrm{E}-06$ & $5.00 \mathrm{E}-04$ \\
\hline TGANTCA_V\$AP1_C & 1121 & JUN & 9 & 0.008 & $9.76 \mathrm{E}-05$ & $1.00 \mathrm{E}-02$ \\
\hline YATGNWAAT_V\$OCT_C & 360 & Uknown & 5 & 0.0139 & $3.36 \mathrm{E}-04$ & $2.95 \mathrm{E}-02$ \\
\hline
\end{tabular}

Figure 2. Activation of IFN response is detected in response to CBL0137 in different tissues of mice via GSEA. A. Venn diagrams showing the number of up (red font) or down (blue font) regulated genes in response to CBL0137 together with gene set names enriched for these genes. The P-value of overlap is shown in parentheses. B. GSEA of curated signaling pathways using the list of genes upregulated in two or more tissues in response to CBL0137. C. GSEA of targets of known transcriptional factors using the list of genes upregulated in all tissues in response to CBL0137. 


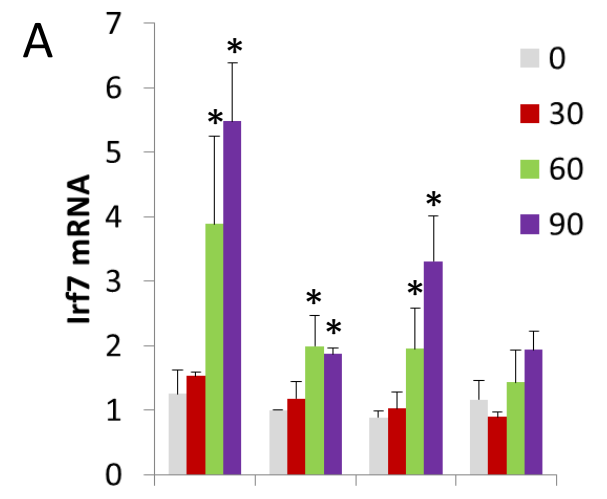

B

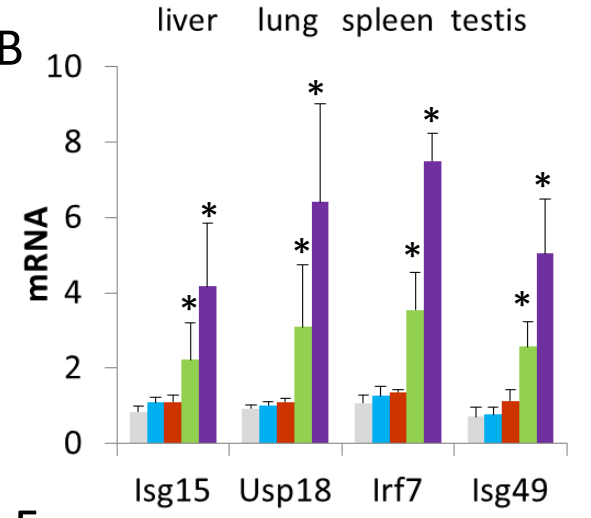

$\mathrm{F}$

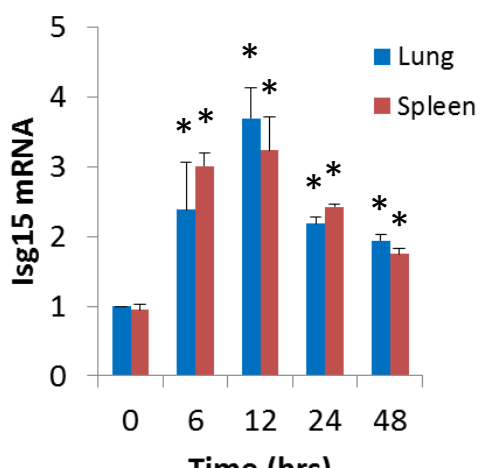

G

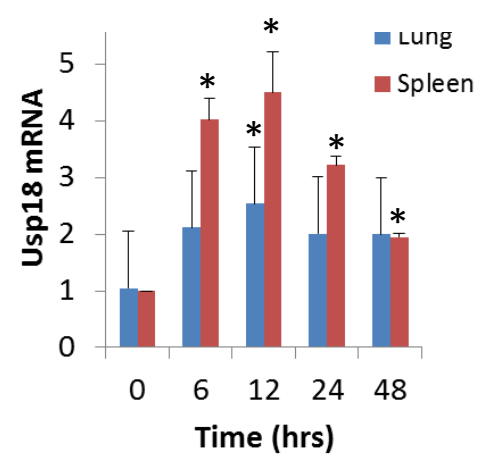

C
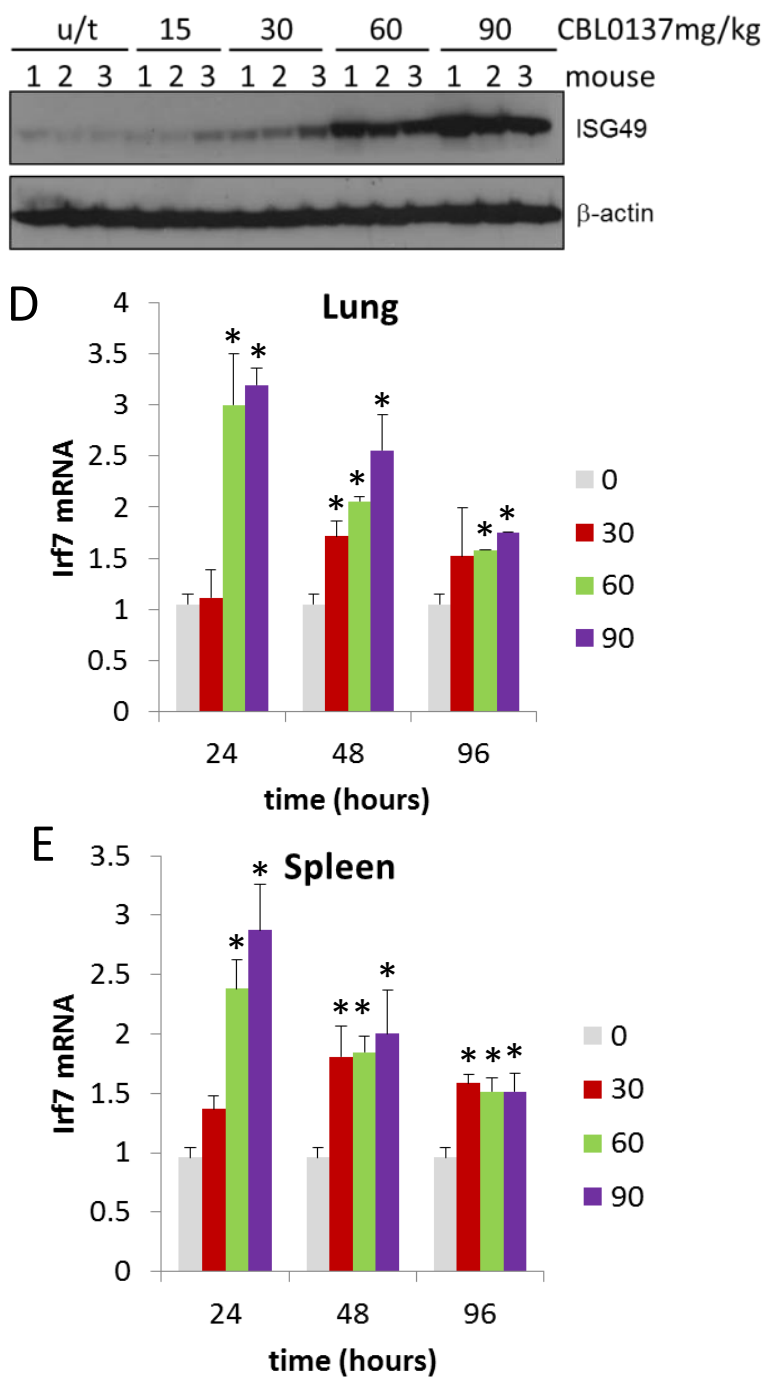

$\mathrm{H}$

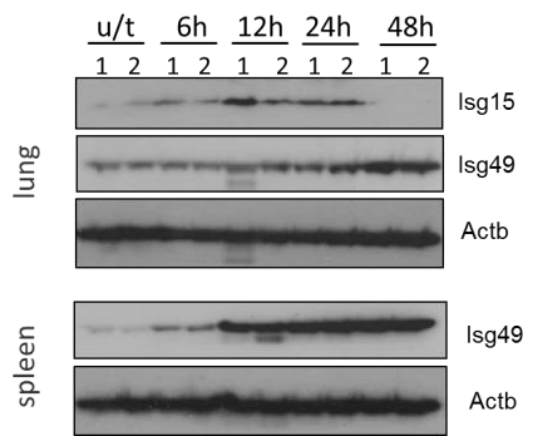

Figure 3. CBL0137 causes increased expression of IFN responsive genes in different tissues of mice. Quantitation of RT-PCR data (A, B, D, E, F, G) shown as fold change upon treatment with different doses of CBL0137 $(\mathrm{mg} / \mathrm{kg}$ ) comparing to vehicle treated control. Mean values from three mice +/-SD. Immunoblotting of mouse plasma (C) or tissue lysates $(\mathrm{H})$. A. Treatment of C57BI/6 mice for 24 hours . B and C. Treatment of NIH Swiss mice for 24 hours . D $\mathrm{H}$. Different time treatment of $\mathrm{C} 57 \mathrm{BI} / 6$ mice. 
A

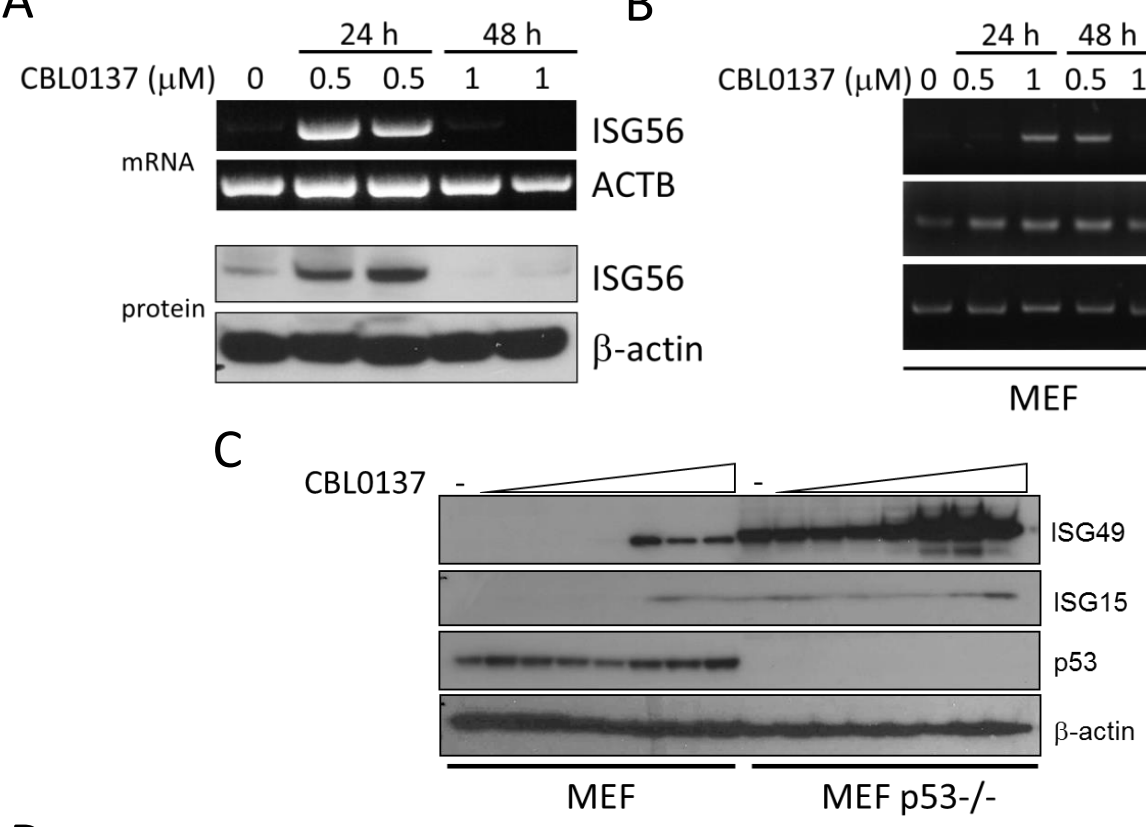

D

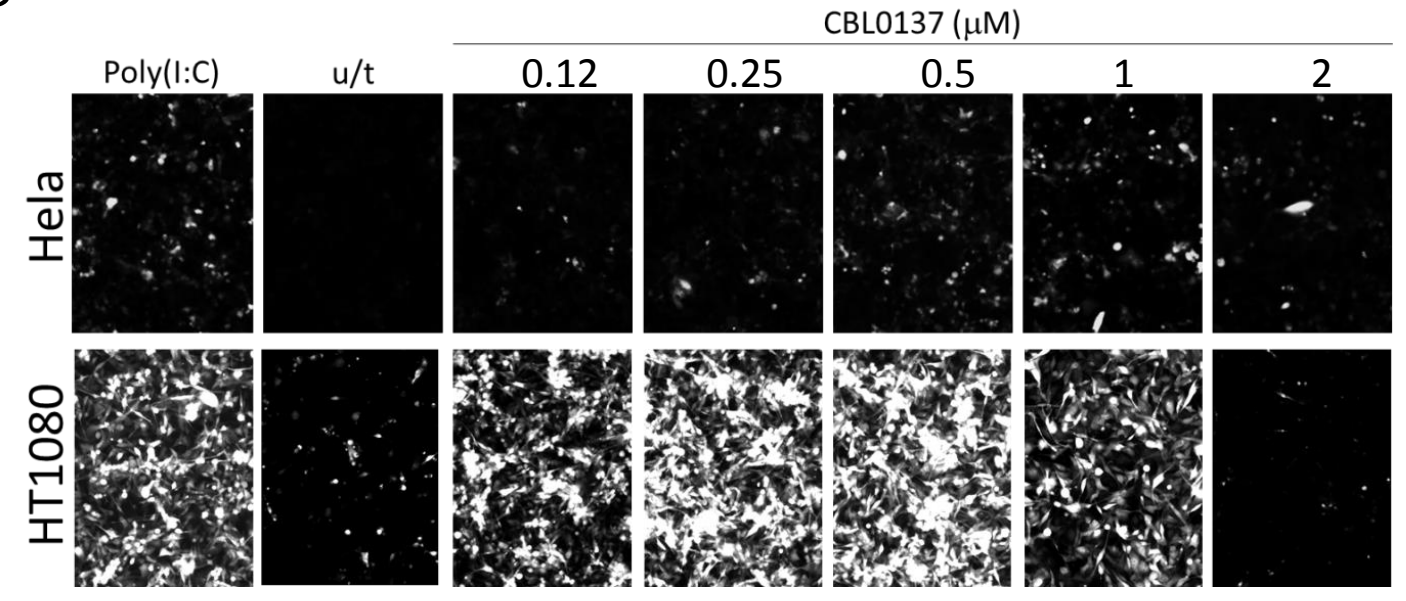

E

Poly(I:C)

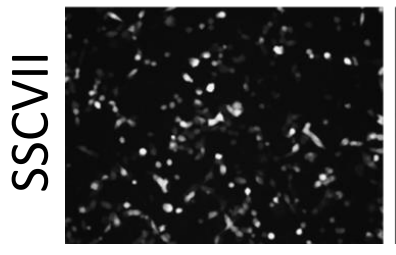

\section{B}

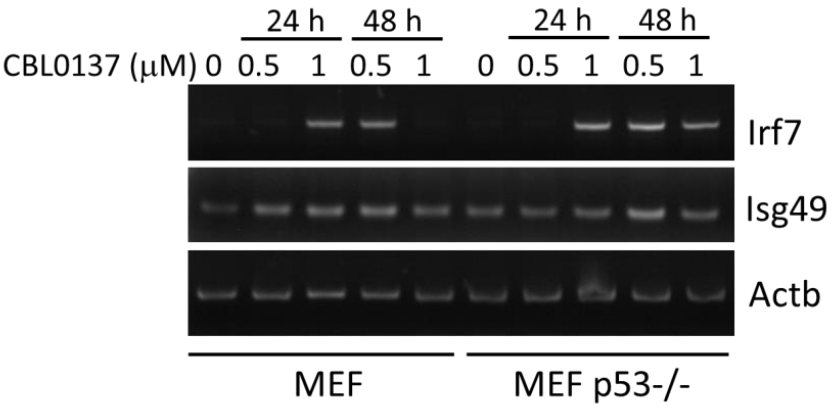


A

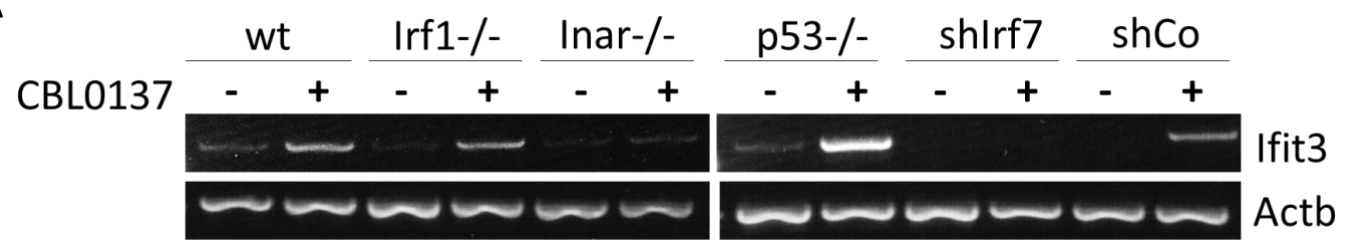

B

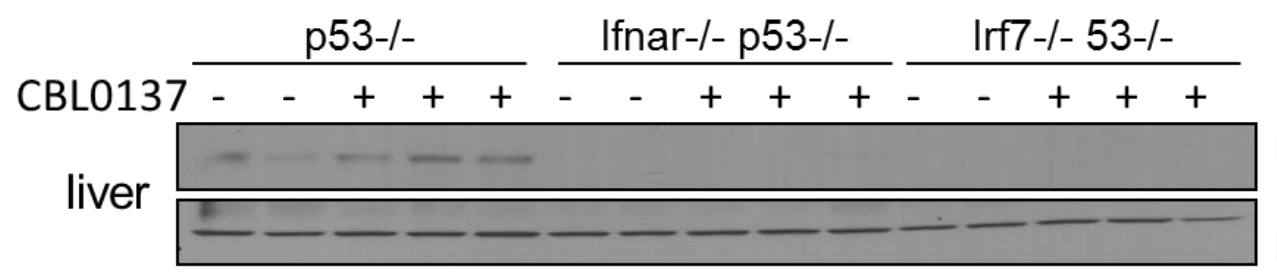

ISG49

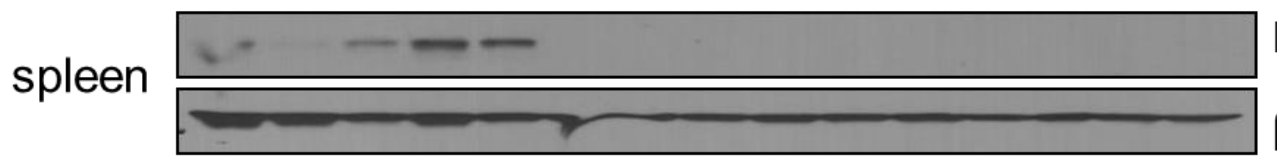

$\beta$-actin

lung

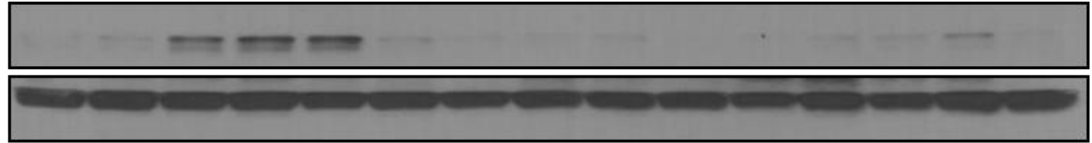

ISG49

$\beta$-actin

ISG49

$\beta$-actin

Figure 5. Induction of IFN-responsive gene by CBL0137 depends on IFN signaling. A. RT-PCR of RNA from MEF cells of different genotype or wild type MEF transduced with control shRNA or shRNA to Irf7 and treated for 24 hours with $0.5 \mu \mathrm{M}$ of CBL0137. B. Immunoblotting of tissue lysates from mice of different genotypes treated with vehicle control ( $n=2$ for each genotype) or $60 \mathrm{mg} / \mathrm{kg}$ CBL0137 $(n=3) 24$ hours before tissue collection. 

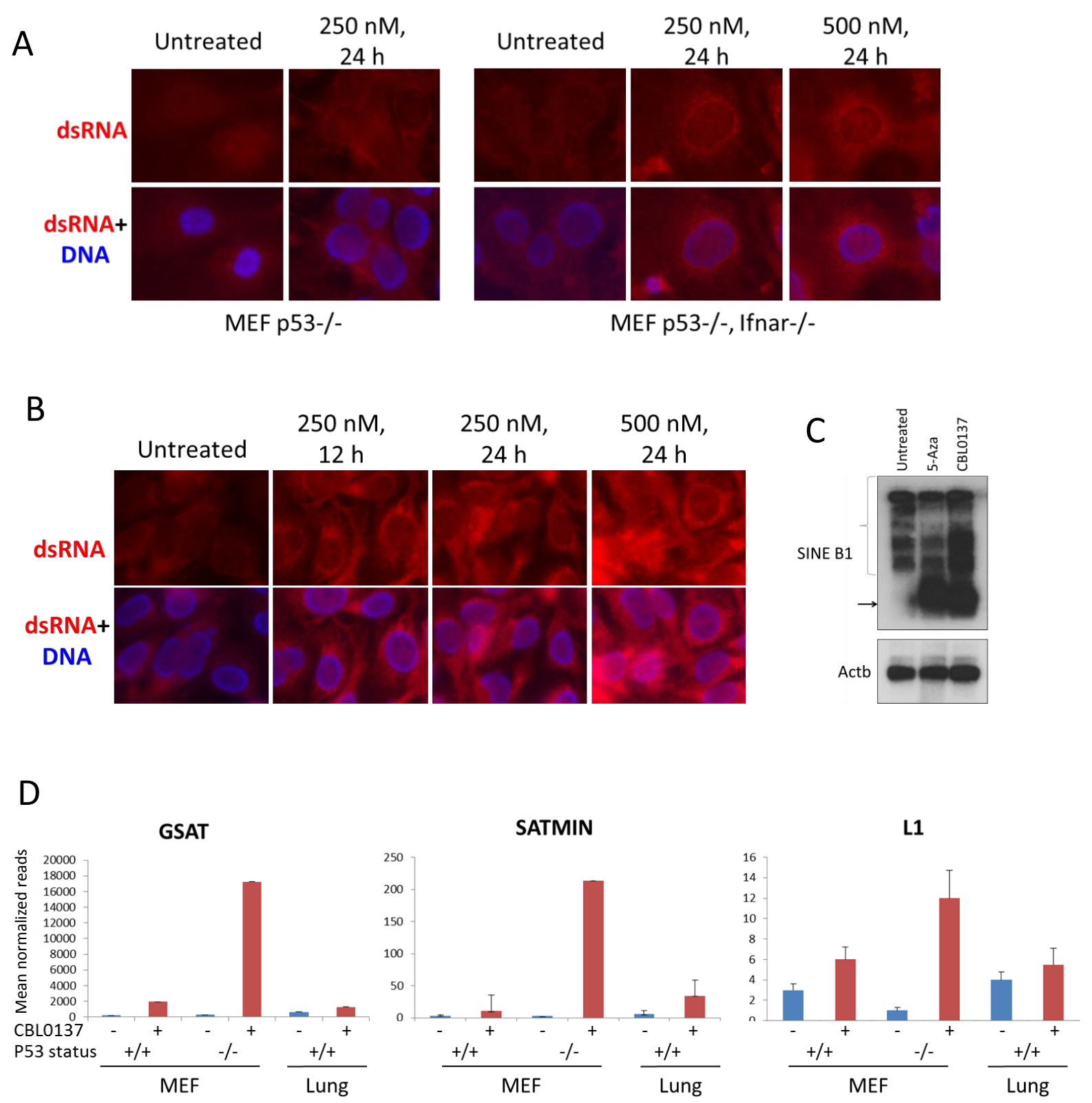

Figure 6. Elevated presence of double-stranded RNA in cells and tissues of mice treated with CBL0137. Immunofluorescent staining of MEF (A) and human HT1080 (B) cells with antibody to dsRNA (red) and Hoeschst (blue). C. Northern blotting of RNA from MEF (p53-/-) treated with either 5-Aza for 72 hours or CBL0137 for 48 hours and hybridized with B1 or beta-actin probes. D. Increase in transcripts corresponding to major (GSAT) or minor (SATMIN) satellites or LINE1 in MEF cells or lung tissue of mice treated with either $1 \mu \mathrm{M}$ or $60 \mathrm{mg} / \mathrm{kg}$ of CBL0137 for 24 hours. 
A
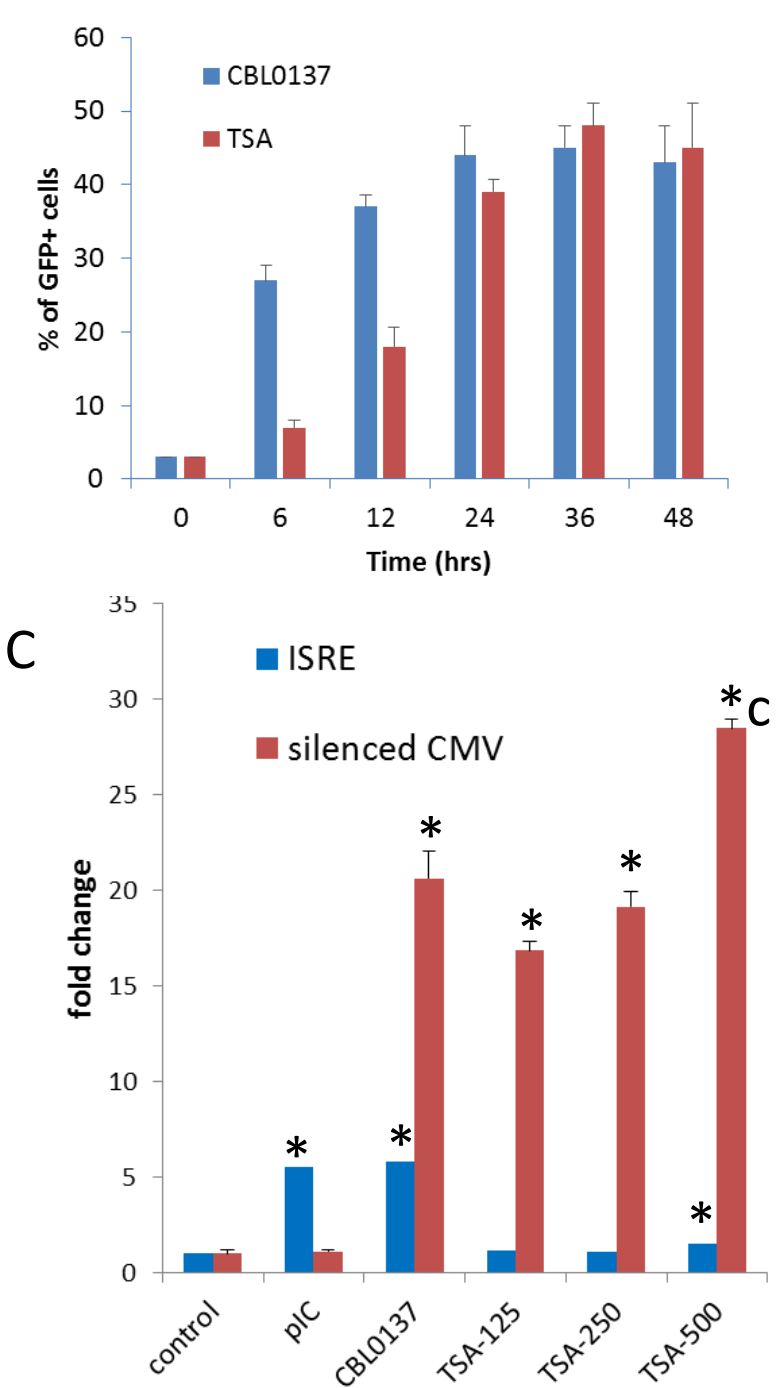

B

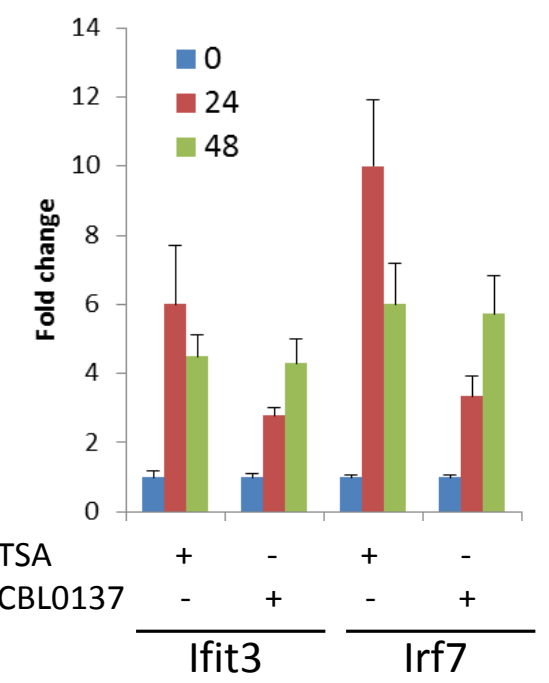

D

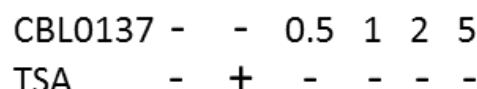

Acetyl-H3

Chromatin-bound $\mathrm{H} 3$

Total H3

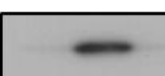

Figure 7. CBL0137 treatment leads to TRAIN due to chromatin opening. A. Increase in the proportion of cells expressing GFP from silenced viral promoter in Hela cells treated with either TSA ( $250 \mathrm{nM}$ ) or CBL0137 (500 nM). B. Changes in the abundance of Ifit3 and Irf7 mRNAs in MEF treated with $500 \mathrm{~nm}$ of TSA or CBL0137 for 24 or 48 hours. Quantitation of RT-PCR, mean of two experiments \pm SDV. All changes are significant versus untreated control $(p<0.05)$. C. Change in the proportion of Hela-TI-ISREmCherry cells positive for mCherry and GFP after 48 hours treatment with the indicated agents. TSA concentrations in $\mathrm{nM}$. Mean of two replicates \pm SDV. ${ }^{*}-p<0.05$ vs untreated control. D. Immunoblotting of extracts of Hela cells treated with TSA (200nM) or different doses of CBL0137 $(\mu \mathrm{M})$ for 24 hours. Acetyl H3 and total H3 were detected in total nuclear extracts, chromatin bound H3 - in chromatin pellet, washed from nucleoplasm with $450 \mathrm{mM} \mathrm{NaCl}$ buffer. 


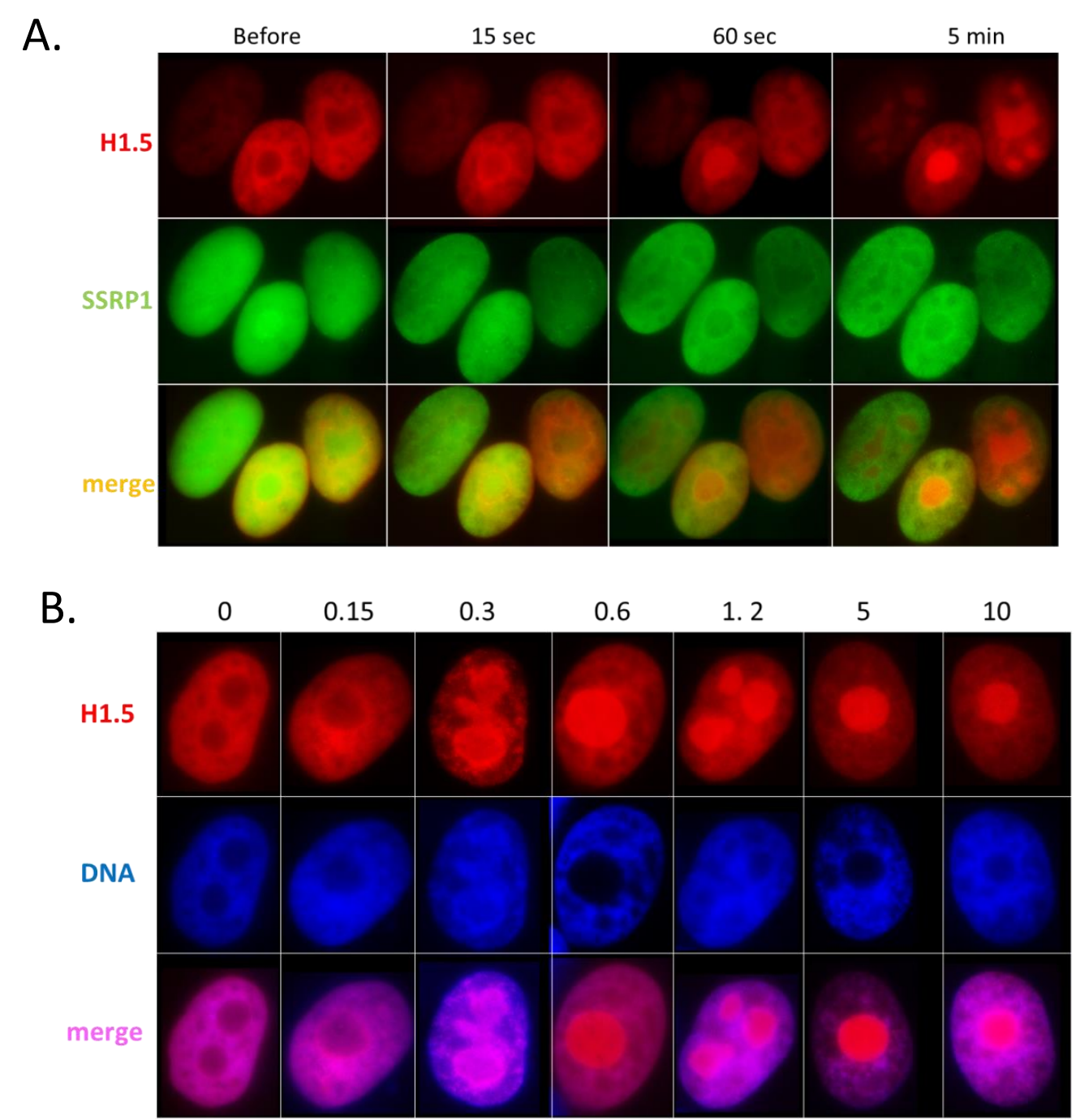

Figure 8. CBL0137 treatment leads to displacement of histone H1. Live cell imaging of HT1080 cells expressing mCherry-tagged H1.5 and GFP-tagged SSRP1. A. Images of nuclei of the same cells at different moments after addition of $1 \mu \mathrm{M}$ CBL0137 to cell culture medium. B. Images of nuclei of cells treated with different concentrations of CBL0137 $(\mu \mathrm{M})$ for 1 hour. 


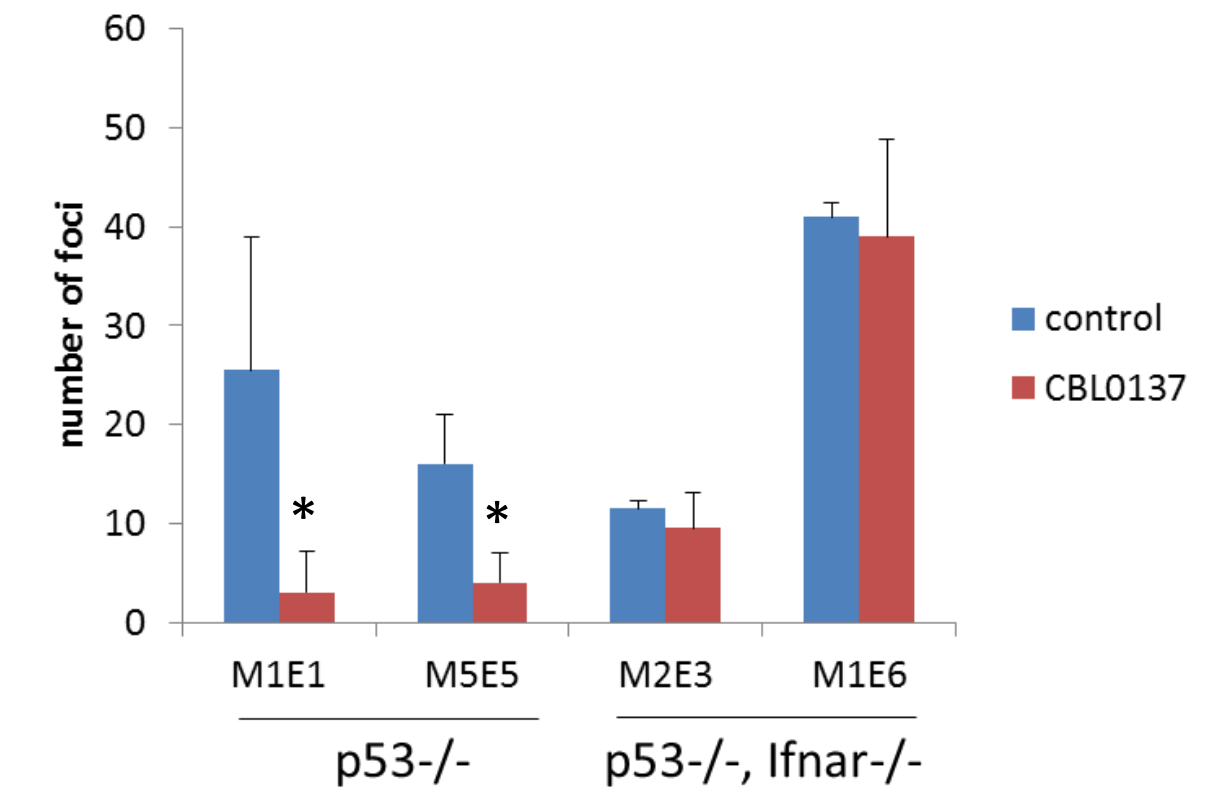

Figure 9. Treatment of cells transduced with H-Rasv12 with CBL0137 leads to the reduction in the number of transformed foci in Ifnar-dependent manner. MEF of different background were transduced with lentiviral HrasV12 followed by treatment with $250 \mathrm{nM}$ CBL0137 for 28 hours. Number of foci was detected on day 10 after transduction. Cultures from two embryos of each genotype were used. Mean of two replicates $\pm S D$. $*$ - $p<0.05$. 
A

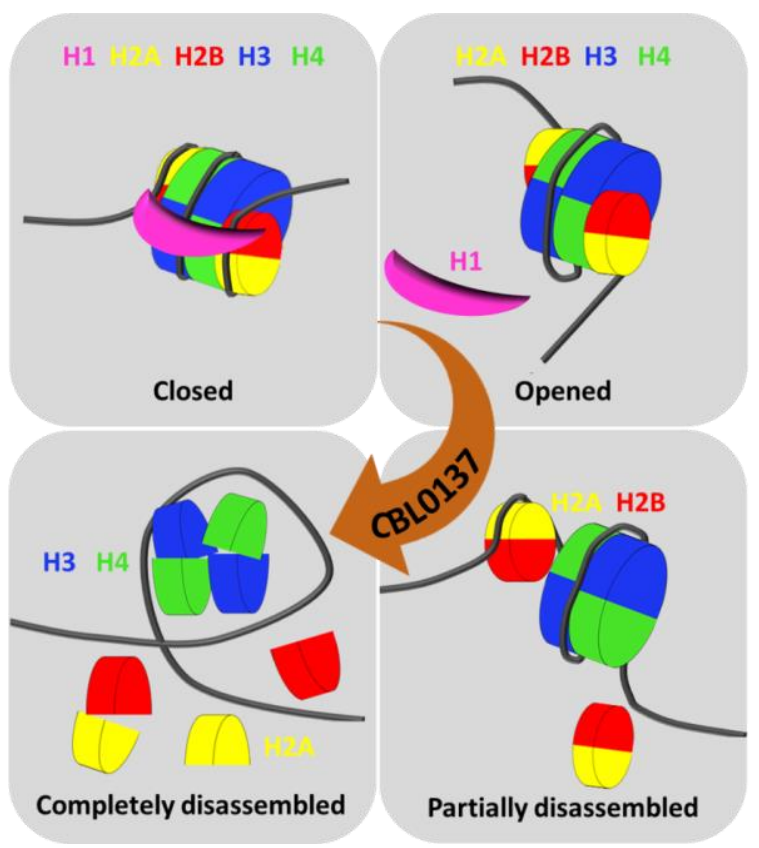

B

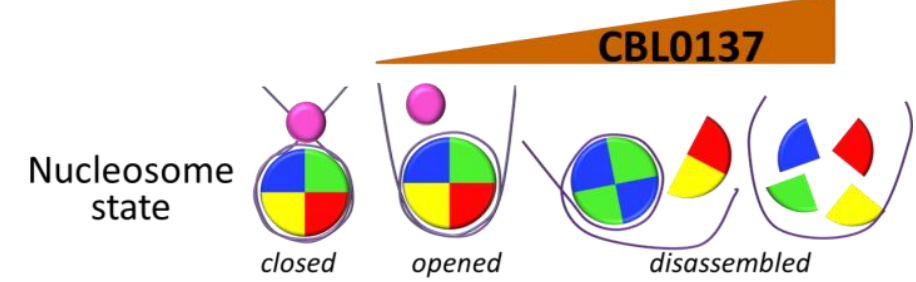

Evicted histones

$\mathrm{H} 1$

"Repeatome" expression

IFN induction

FACT binding to unfolded nucleosome

B-DNA to Z-DNA transition

FACT binding to Z-DNA

Cell death

Time of death (h)

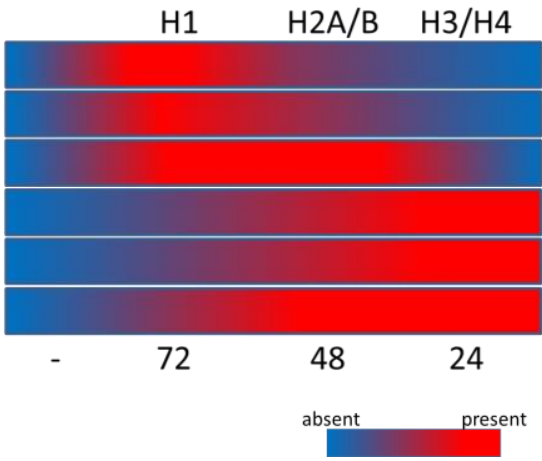

Figure 10. Proposed scheme of nucleosome states in the absence and presence of increasing concentrations of CBL0137 (A) and associated biological processes in cells (B). 